\title{
POSTERS PRIMES \\ AU XXIe CONGRES DE LA SALF
}

Clermond-Ferrand - Décembre 2004

CREATION D'UN MODELE "IN VITRO" POUR L'ETUDE DE L'EFFET DES GENO-

TOXIQUES SUR LA CELLULE GERMINALE MALE.

J.E. PERRIN, M. DE MEO, P. DURAND, J.M. FEUERSTEIN, A. BOTTA, M.R. GUICHAOUA, J.L. BERGE-LEFRANC

Poster P3

RECHERCHE D'ANTIGENES SPERMATIQUES POUR LA MISE AU POINT D'UN VACCIN CONTRACEPTIF VISANT A LIMITER LES PULLULATIONS DU CAMPAGNOL TERRESTRE Arvicola terrestris

E. GRIGNARD, P. VERNET, J. DREVET

Poster P6

ETUDE DE DEUX MARQUEURS DE L'APOPTOSE ET DE LA SEGREGATION MEIOTIQUE SUR DES SPERMES DE PATIENTS PORTEURS DE TRANSLOCATION CHROMOSOMIQUE.

F. BRUGNON, E. VAN ASSCHEV, B. SIONS, L. JANNY, B. AUBLET-CUVELLIER,

I. LIEBAERS, A. VAN STEIRTEGHEM, D. BOUCHER

Poster P13

EVENEMENTS DE FILIATION ET INFERTILITE MASCULINE

M. JAOUL, D. MOLINA GOMES, M. ALBERT, N. LEDEE-BATAILLE, M. BAILLY, J. SELVA

Poster P20

INFERTILITE MASCULINE : EPIDEMIOLOGIE DANS LE SUD TUNISIEN

A. BAHLOUL, A. MALLEK, Y. MHADHEB, A. SAHNOUN, H. KETATA, M.N. MHIRI

Poster P21

CINETIQUE ET CARACTERISATION DU PHENOMENE "APOPTOSIS-LIKE" INDUIT AU COURS DE LA CONGELATION DES SPERMATOZOÏDES BOVINS

G. MARTIN, O. SABIDO, P. DURAND, R. LEVY

Poster P23 


\section{LISTE DES POSTERS PAR ORDRE ALPHABETIQUE ( $1^{\text {er }}$ Auteur)}

\begin{tabular}{|c|c|c|}
\hline NOM & TITRE & N'POSTER \\
\hline AKNIN-SEIFER I. & $\begin{array}{l}\text { Comparaison de deux kits de détection des microdélétions du } \\
\text { chromosome } \mathrm{Y} \text {. }\end{array}$ & 18 \\
\hline AKNIN-SEIFER I. & Intérêt de la DHPLC dans la mise en évidence des copies de DAZ. & 19 \\
\hline BEN ABDALLAH F. & $\begin{array}{l}\text { Effets des polyphenols contenus dans l'huile des noyaux des dattes } \\
\text { sur la mobilité des spermatozoïdes exposés à un stress oxydant in } \\
\text { vitro. }\end{array}$ & 51 \\
\hline BRAYOTEL F. & $\begin{array}{l}\text { Taux de fragmentation de l'ADN des spermatozoïdes : mise au point } \\
\text { d'une technique, valeur diagnostique et pronostique. }\end{array}$ & 9 \\
\hline BRITAN A. & $\begin{array}{l}\text { Analyse de l'expression différentielle du gène GPX5 murin, un } \\
\text { marqueur de la différenciation épididymaire. }\end{array}$ & 5 \\
\hline BRUGNONF. & $\begin{array}{l}\text { Etude de deux marqueurs de l'apoptose et de la ségrégation } \\
\text { méiotique sur des spermes de patients porteurs de transiocation } \\
\text { chromosomique. }\end{array}$ & 13 \\
\hline BRUGNON F. & Intérêt de la vésiculographie chez lhomme infertile. & 47 \\
\hline BUJANL. & $\begin{array}{l}\text { Caractéristiques spermiologiques des hommes infectés par le virus } \\
\text { de l'immunodéficience humaine VIH. }\end{array}$ & 27 \\
\hline BUJAN L. & Facteurs associés à l'excrétion du VIH-1 dans le sperme. & 28 \\
\hline CLAVERT A. & $\begin{array}{l}\text { Analyse d'une enquête menée auprès des hommes conservant leur } \\
\text { sperme au CECOS Alsace. }\end{array}$ & 36 \\
\hline DELAVIERRE D. & $\begin{array}{l}\text { Insuffisance de désir sexuel chez l'homme, intérêt du bilan hormonal. } \\
\text { A propos de } 59 \text { patients. }\end{array}$ & 50 \\
\hline DELAVIERRE D. & $\begin{array}{l}\text { Bloc en } 21 \text { hydroxylase : une cause rare d'hypofertilité masculine et } \\
\text { de tumeur du testicule. }\end{array}$ & 41 \\
\hline DEMAILLY M. & $\begin{array}{l}\text { Corrélation entre le nombre d'anomalies chromosomiques et } \\
\text { l'importance de l'oligospermie. }\end{array}$ & 12 \\
\hline DROUINEAUD $V$. & Globozoospermie : à propos de 3 cas. & 26 \\
\hline DUPARC C. & $\begin{array}{l}\text { Inhibine B plasmatique, marqueur des tumeurs testiculaires à cellules } \\
\text { de Leydig. }\end{array}$ & 8 \\
\hline FOLOPE V. & $\begin{array}{l}\text { Etude de l'impact de la dihydrotestostérone sur la steroidogénèse } \\
\text { leydigienne. }\end{array}$ & 1 \\
\hline GIORGETTI C. & $\begin{array}{l}\text { Taux cumulatif de grossesses après ICSI utilisant uniquement des } \\
\text { spermatozoïdes testiculaires congelés chez } 51 \text { hommes présentant } \\
\text { une azoospermie non obstructive. }\end{array}$ & 30 \\
\hline GRIGNARD E. & $\begin{array}{l}\text { Recherche d'antigènes spermatiques pour la mise au point d'un } \\
\text { vaccin contraceptif visant à limiter les pullulations du campagnol } \\
\text { terrestre Arvicola Terrestris. }\end{array}$ & 6 \\
\hline GUY L. & $\begin{array}{l}\text { Les cellules neuro-endocrines du veru-montanum : étude comparative } \\
\text { immunohistochimique. }\end{array}$ & 46 \\
\hline IBALA S. & $\begin{array}{l}\text { Recherche des microdélétions du bras long du chromosome Y chez } \\
\text { des hommes infertiles. }\end{array}$ & 17 \\
\hline
\end{tabular}




\begin{tabular}{|c|c|c|}
\hline JAOUL $M$. & Evènements de filiation et infertilité masculine. & 20 \\
\hline $\begin{array}{l}\text { LEFEBVRE } \\
\text { KHALIL V. }\end{array}$ & $\begin{array}{l}\text { Apport de l'autoconservation de sperme dans la prise en charge des } \\
\text { oligozoospermies extrêmes. }\end{array}$ & 35 \\
\hline MALLEK A. & Le rhabdomiosarcome para-testiculaire. & 42 \\
\hline MALLEK A. & Infertilité masculine : épidèmiologie dans le sud tunisien. & 21 \\
\hline MALLEK A. & Syndrome de klinefelter et infertilité. & 10 \\
\hline MALLEK A. & $\begin{array}{l}\text { Intérêt de la cure de varicocèle chez l'adulte d'âge supérieur à } 50 \\
\text { ans. }\end{array}$ & 44 \\
\hline MALLEK A. & Le pseudo hermaphrodisme masculin (4 cas). & 45 \\
\hline MARTIN G. & $\begin{array}{l}\text { Induction de l'externalisation des résidus de phosphatidylserine dans } \\
\text { le spermatozoïde humain par le ionophore calcique A23187. }\end{array}$ & 22 \\
\hline MARTIN G. & $\begin{array}{l}\text { Cinétique et caractérisation du phénomène " apoptosis-like" induit } \\
\text { au cours de la congélation des spermatozoïdes bovins. }\end{array}$ & 23 \\
\hline MARTIN G. & $\begin{array}{l}\text { Variations saisonnières et inter-individuelles pour différents } \\
\text { paramètres du sperme bovin en France. }\end{array}$ & 24 \\
\hline $\begin{array}{l}\text { METZLER- } \\
\text { GUILLEMAINE C. }\end{array}$ & $\begin{array}{l}\text { Délai moyen pour concevoir en Assistance Médicale à la Procréation } \\
\text { avec don de spermatozoïdes. }\end{array}$ & 34 \\
\hline MHADHEB Y. & $\begin{array}{l}\text { Devenir sexuel des patients opérés par dérivation urinaire externe } \\
\text { continente. }\end{array}$ & 49 \\
\hline MHADHEB Y. & L'éléphantiasis scrotal. & 38 \\
\hline MHADHEB Y. & Chromosome $Y$ dycentrique. & 15 \\
\hline MIEUSSET R. & $\begin{array}{l}\text { Effets de la position et de l'habillement sur la dynamique de la } \\
\text { température scrotale. }\end{array}$ & 39 \\
\hline MIEUSSET R. & $\begin{array}{l}\text { Hypospadias: conséquences psychosociales, urologiques, sexuelles } \\
\text { et reproductives à l'âge adulte. }\end{array}$ & 40 \\
\hline MIEUSSET R. & $\begin{array}{l}\text { Les hémi-scrotums droit et gauche sont-ils fonctionnellement } \\
\text { equivalents? }\end{array}$ & 37 \\
\hline PASSAVANTI G. & La microlithiase testiculaire : pathogénèse et aspects cliniques. & 43 \\
\hline PERRIN J.E. & $\begin{array}{l}\text { Création d'un modèle "in vitro " pour l'étude de l'effet des } \\
\text { génotoxiques sur la cellule germinale mâle. }\end{array}$ & 3 \\
\hline PETIT F. & $\begin{array}{l}\text { La détermination du taux d'aneuploïdie dans les spermatozoïdes } \\
\text { peut-elle constituer un test prédictif avant l'ICSI? }\end{array}$ & 11 \\
\hline RODDIER H. & $\begin{array}{l}\text { Evaluation de la cytotoxicité in vitro de l'Alachlore (2-chloro-N-(2,6- } \\
\text { diethylphenyl)- } \mathrm{N} \text {-(méthoxyméthyl)-acétamide) en prenant le } \\
\text { spermatozoide humain comme modèle. }\end{array}$ & 4 \\
\hline SAEZ F. & $\begin{array}{l}\text { Gènes cibles des LXRs (Liver X Receptors) dans l'épididyme murin : } \\
\text { étude in vitro sur un modèle cellulaire. }\end{array}$ & 7 \\
\hline SAVAREUXL. & $\begin{array}{l}\text { Evaluation de la fonction érectile après chirurgie de l'hypertrophie } \\
\text { bénigne de prostate. }\end{array}$ & 48 \\
\hline
\end{tabular}




\begin{tabular}{|l|l|c|}
\hline SCHUBERT B. & $\begin{array}{l}\text { Etude par FISH de cellules somatiques et germinales du tissu } \\
\text { testiculaire de deux hommes porteurs de chromosome } Y \text { pseudo } \\
\text { dicentrique. }\end{array}$ & 16 \\
\hline SELVA J. & $\begin{array}{l}\text { Le risque chromosomique pour un patient porteur d'une translocation } \\
t(X ; 2) \text { concerne non seulement la translocation mais aussi la } \\
\text { ségrégation } X Y .\end{array}$ & 14 \\
\hline SION B. & $\begin{array}{l}\text { Quantification des prostasomes par cytométrie en flux. Relation avec } \\
\text { les paramètres spermatiques. }\end{array}$ & 25 \\
\hline SOARES P. & $\begin{array}{l}\text { ICSI : risques potentiels de la technique et problèmes éthiques } \\
\text { soulevés par la technique. }\end{array}$ & 33 \\
\hline TIELMANS A. & $\begin{array}{l}\text { Etude de la réponse hormonale testiculaire à l'administration de } \\
\text { doses croissantes de gonadotrophines chorioniques (hCG) chez le } \\
\text { témoin sain. }\end{array}$ & 2 \\
\hline VIRAN-KLUN I. & $\begin{array}{l}\text { En lCSl, la préparation des spermatozoïdes testiculaires à } \\
\text { l'hypotaurine améliore leur mobilité, le développement embryonnaire } \\
\text { au stade blastocyste et le taux de grossesse. }\end{array}$ & 29 \\
\hline VIRAN-KLUN I. & $\begin{array}{l}\text { Intérêt de la cryoconservation des ovocytes matures chez des } \\
\text { couples pour lesquels aucun spermatozoïde n'a été retrouvé le jour } \\
\text { de la fécondation in vitro. }\end{array}$ & 32 \\
\hline ZORN B. & $\begin{array}{l}\text { Naissance d'enfants d'hommes infertiles azoospermiques avec taux } \\
\text { élevé de la FSH sérique. }\end{array}$ & 31 \\
\hline
\end{tabular}




\title{
Etude de l'impact de la dihydrotestostérone sur la stéroïdogénèse Leydigienne
}

\author{
V. FOLOPE, H. LEFEBVRE, J.M. KUHN \\ Service d'Endocrinologie, Diabète et Maladies Métaboliques, Centre d'Investigation Clinique INSERM 204, \\ CHU Rouen et INSERM U413, Université de Rouen
}

La dihydrotestostérone (DHT), produit de "fin de chaine", de la stéroïdogenèse leydigienne est susceptible d'y exercer un rétro-contrôle local. Pour tester cette hypothèse, les taux plasmatiques de $T$ et d'E2 ont été mesurés avant puis 24,48 et 72 heures après injection IM de $5000 \mathrm{UI}$ d'hCG dans un groupe de 12 hommes adultes sains étudiés en trois occasions. Elles ont été séparées chacune de 2 semaines et réalisées dans un ordre aléatoire: hCG seule (toujours injectée à J1), DHT (250 mg/j pendant 8 jours) à partir de $\mathrm{J}-5+\mathrm{hCG}$, un antiandrogène pur (nilutamide $300 \mathrm{mg} / \mathrm{j}$ pendant 4 jours à partir de J0) + hCG. T, DHT et E2 ont été mesurées par immunoluminescence (Immulite 2000, DPC), la séparation de T et DHT a été réalisée sur colonne de chromatographie Sep-Pack. Les résultats sont mentionnés dans le tableau :

Le taux plasmatique de DHT est respectivement de $2,1+1$ 0,5 et de $10,9+/-1,7 \mathrm{nmol} / /$ sans et avec traitement par DHT. ils ne sont pas significativement modifiés par l'hCG. Le rapport E2/T (en \% du chiffre de base) s'élève de
$162+/-9$ (hCG seule), $189+/-13$ (hCG + Nilutamide) et $50+/-12$ (hCG + DHT). Le blocage du récepteur androgénique n'a pas d'influence sur l'ascension du taux de $T$ induite par l'hCG. Ceci contraste avec la majoration du pic de $T$, précédemment observé après blocage de l'activité 5a Réductase par le Finastéride [1]. Le traitement par DHT induit un abaissement de la $T$ basale par frénation gonadotrope [2], ne modifie pas le pic d'élévation de la $T$ en réponse à l'hCG mais réduit l'aromatisation de la $\mathrm{T}$ en E2. En conclusion, à taux physiologiques ou pharmacologiques, la DHT n'a pas d'influence sur la production de $T$ en réponse à l'hCG. A l'inverse, aux taux plasmatiques obtenus lors de traitements par DHT, ce stéroïde apparait limiter la capacité d'aromatisation de la T en E2 induite par l'hCG par la cellule de Leydig testiculaire humaine.

\section{REFERENCES}

1. CASTRO-MAGANA M ET AL : J Androl 1996, $17: 516$.

2. KUHN JM ET AL : J Clin Endocrinol Metab 1984, 58 : 231.

\begin{tabular}{lcccc}
\hline & T base $\mathbf{n m o l} / \mathbf{l}$ & T pic $\mathbf{n m o l} / \mathbf{I}$ & E2 base pmol/l & E2 pic pmol/l \\
\hline hCG & $15,7+/-1,0$ & $33,9+/-2,4$ & $119+/-20$ & $410+/-40$ \\
hCG + Nilutamide & $16,4+/-1,9$ & $33,5+/-3,3$ & $101+/-28$ & $390+/-45$ \\
hCG + DHT & $9,0+/-2,1$ & $35,1+/-3,5$ & $110+/-28$ & $200+/-25$ \\
\hline
\end{tabular}




\title{
Etude de la réponse hormonale testiculaire à l'administration de doses croissantes de gonadotro- phines chorioniques (hCG) chez le témoin sain
}

\author{
A. TIELMANS, H. LEFEBVRE, J.M. KUHN
}

Service d'Endocrinologie, Diabète et Maladies Métaboliques, Centre d'Investigation Clinique INSERM 204, CHU Rouen et INSERM U413, Université de Rouen

La production de testostérone ( $T$ ) et de 17- $ß$ estradiol (E2) par le testicule adulte humain normal est placé sous le contrôle de la sécrétion de LH hypophysaire. Cette gonadotrophine agit par activation d'un récepteur métabotropique positivement couplé à l'adénylyl-cyclase via une protéine Gs. La gonadotrophine chorionique (hCG), hormone placentaire, stimule la stéroïdogenèse testiculaire par activation du même récepteur que la $\mathrm{LH}$, le récepteur LH/hCG. L'exploration fonctionnelle de la stéroïdogenèse testiculaire utilise des doses pharmacologiques (5000 UI) d'hCG. L'amplitude de la réponse hormonale, mesurée pendant les 3 jours suivant l'injection est la résultante d'un effet stimulant et d'un phénomène de désensibilisation de l'hCG, lié à la fois à sa longue demi-vie plasmatique (72 heures) et à son irréversible liaison au récepteur leydigien. Nous avons donc cherché à évaluer si l'emploi de doses inférieures d'hCG, susceptibles de limiter les effets "désensibilisateurs" parasites, permettait d'obtenir une information pertinente sur le potentiel sécrétoire de la cellule de Leydig de l'homme adulte. Les taux plasmatiques de $T$ et d'E2 ont été mesurés cherz 8 témoins sains avant puis $1,3,5,24,48$ et 72 heures après injection dans un ordre aléatoire, de solvant seul ou de 50,500 et $5000 \mathrm{UI}$ d'hCG. T et E2 ont été mesurées par immunoluminescence (Immulite 2000, DPC) et les taux de gonadotrophines plasmatiques par méthodes immunoradiométriques (FSH et LH Assays, Amerlite). 48 heures après l'injection, l'amplitude de l'élévation de la $T$ est proportionnelle à la dose d'hCG administrée $(r=0.99, p<0.001)$. Il existe une corrélation positive similaire $(r=0,98, p<0,001)$ entre l'estradiolémie à la 24ème heure du test et la dose d'hCG utilisée. A cette heure, dès la dose de $500 \mathrm{UI}$ d'hCG la valeur du taux d'E2 $(39+/-11 \mathrm{pg} / \mathrm{ml})$, est significativement $(p<0.01)$ différente des taux de base $(18+/-6 \mathrm{pg} / \mathrm{ml})$. En conclusion, jugée sur l'ascension du taux de $T$ plasmatique, la réponse du testicule endocrine est optimalement évaluée 72 heures après injection de 5000 UI d'hCG alors qu'elle peut être pertinemment appréciée par l'élévation de l'E2 mesurée 24 heures après l'injection d'une dose 10 fois plus faible de stimuline, raccourcissant la durée du test et limitant potentiellement l'effet "désensibilisateur" de l'hCG. 


\title{
Création d'un modèle "in vitro" pour l'étude de l'effet des génotoxiques sur la cellule germinale mâle
}

\author{
J.E. PERRIN1, M. DE MEO1, P. DURAND2, J.M. FEUERSTEIN3, A. BOTTA1, M.R. GUICHAOUA1, \\ J.L. BERGE-LEFRANC1 \\ 1 Laboratoire de Biogénotoxicologie et Mutagenèse Environnementale (EA1784), IFR PMSE 112, Faculté de \\ Médecine, Marseille ; 2 UMR INSERM 418/INRA 1245/UCBL1, Hôpital Debrousse, Lyon ; 3 C.F.R.E.M.C, \\ Faculté de Médecine, Marseille
}

On observe depuis ces dernières décennies, dans de nombreuses espèces animales et en particulier chez l'Homme, une altération significative des paramètres du sperme. L'implication de toxiques environnementaux liés au développement industriel est l'un des facteurs désignés comme responsables de ce phénomène.

Dans son mécanisme physiologique, la maturation des cellules germinales mâles est accompagnée de phénomènes de recombinaison génétique qui sont initiés précocement durant la méiose par des cassures doubles brins des molécules d'ADN suivies de processus de réparations.

Une autre propriété importante des cellules germinales est le taux élevé d'apoptose qui concerne naturellement près de $20 \%$ des spermatozoïdes mûrs.

L'influence de l'environnement et en particulier des toxiques chimiques ou physiques est, à ce jour, mal définie et l'étude du rôle de ces facteurs nécessite la mise en place de modèles cellulaires afin de compléter les études in vivo réalisées chez l'animal.

Nous avons mis au point un système basé sur la co-culture in vitro de cellules germinales et de cellules de Sertoli de rat. Ce système permet la différenciation des cellules germinales à partir du stade spermatocyte pré-leptotène jusqu'au stade spermatocyte pachytène d'une part, et du stade spermatocyte pachytène jusqu'au stade spermatide ronde d'autre part. L'utilisation de ces deux cultures permet donc d'appréhender in vitro la quasi-totalité des étapes de différenciation méiotique des cellules germinales mâles. Le stade méiotique des cellules germinales a pu être déterminé par l'étude morphologique des complexes synaptonémaux marqués par immunocytochimie. L'évolution des cassures de l'ADN spécifiques des cellules germinales en cours de différenciation est étudiée par le test des comètes (version alcaline). Le niveau d'apoptose est suivi au long de la culture par la quantification de l'activité caspase 3 et 7 .

Au cours de la différenciation cellulaire germinale, la cinétique du nombre des cassures de l'ADN sur une période de 16 jours est une diminution exponentielle du nombre des coupures, que l'on peut corréler avec la réparation des cassures double-brin. Ces résultats indiquent que le modèle cinétique proposé permet, à l'état physiologique, l'étude des mécanismes de réparation, de recombinaison et de leurs modifications. II peut donc aussi constituer un modèle pour l'étude détaillée des mécanismes de mutagenèse et de toxicologie génétique sur les cellules germinales. Ce modèle présente l'avantage d'approcher in vitro les conditions d'interactions cellulaires présentes in vivo dans le tube séminifère, notamment entre les cellules de Sertoli et les cellules germinales en différenciation. Dans les conditions d'exposition aux génotoxiques, ce système pourrait ainsi permettre d'étudier les profils d'expression d'un certain nombre de gènes, en particulier les gènes impliqués dans la réparation de l'ADN.

\section{REFERENCES}

1. OOSTERHUIS GJ, MULDER AB, KALSBEEK-BATENBURG E, LAMBALK CB, SCHOEMAKER J, VERMES I. : Measuring apoptosis in human spermatozoa: a biological assay for semen quality ? Fertil Steril. 2000 Aug; 74(2) : 245-50

2. WEISS M, VIGIER M, HUE D, PERRARD-SAPORI MH, MARRET C, AVALLET C, DURAND P. : Pre- and Post-Meiotic Expression of Male Germ-Cell-Specific Genes Throughout 2-Weeks Cocultures of rat Germinal and Sertoli Cells. Biol Reprod 57, 68-76 (1997).

3. OLIVE PL. : The comet assay. An overview of techniques. Methods Mol Biol. 203, 179-94 (2002). 


\title{
Evaluation de la cytotoxicité in vitro de l'alachlore (2- chloro- $\mathrm{N}$-(2,6-diéthyphenyl)- $\mathrm{N}$-(méthoxyméthyl)-acétamide) en prenant le spermatozoïde humain comme modèle
}

\author{
H. RODDIER1, L. OUCHCHANE2, C. ARTONNE1, C. DELEINE3, M.P. VASSON3, G. GRIZARD1
}

1 Laboratoire de biologie de la reproduction, EA 975, faculté de médecine, Clermont-Ferrand ; 2 Département de Santé Publique, CHU, Clermont-Ferrand ; 3 Laboratoire de Biochimie, Biologie moléculaire et nutrition, EA 2416, Faculté de Pharmacie, Clermont-Ferrand

\section{INTRODUCTION}

Le spermatozoïde humain a été utilisé comme modèle cellulaire pour évaluer in vitro la cytotoxicité d'un herbicide, l'Alachlore (2-chloro-N-(2,6-diéthylphenyl)-N(méthoxyméthyl)-acétamide).

\section{MATERIEL ET METHODES}

Les spermatozoïdes provenant de spermes normaux selon les critères de l'OMS ont été sélectionnés sur gradient de densité (Percoll) et ceux contenus dans la fraction la plus dense (Percoll 95\%) ont été utilisé pour l'étude. Les spermatozoïdes ont été incubés avec 4 doses d'Alachlore $(0,18 \mathrm{mM}$ à $1,85 \mathrm{mM})$ pendant $5,30,60$ et 120 minutes. La cytotoxicité de l'Alachlore a été appréciée à partir des paramètres suivants : le mouvement des spermatozoïdes analysé par CASA (Computer Assisted Sperm motion Anamysis); la production de dérivés actifs de l'oxygène (DAO) par chimiluminescence afin d'évaluer le stress oxydant; l'externalisation de la phosphatidylsérine (PS) au niveau de la membrane plasmique, par marquage à l'Annexine $V$ et au Propidium lodide en cytométrie de flux, comme marqueur d'apoptose.

\section{RESULTATS}

Les paramètres du mouvement traduisant la vélocité des spermatozoïdes diminuent de façon monotone avec les durées d'incubation et les concentrations croissantes d'Alachlore, et ces 2 facteurs interagissent significativement. La production de DAO et la population de spermatozoïdes vivants ayant externalisé la PS sint significativement augmentées avec les doses les plus élevées d'Alachlore.

\section{CONCLUSION}

De par sa fonction cinétique spécifique, le spermatozoïde humain apparaît comme un modèle cellulaire adapté pour évaluer la cytotoxicité de l'Alachlore. De plus, nos résultats préliminaires suggèrent que l'Alachlore est responsable d'un stress oxydant pouvant entraîner l'apoptose des spermatozoïdes. 


\title{
Analyse de l'expression différentielle du gène GPX5 murin, un marqueur de la différenciation épididymaire
}

\author{
A. BRITAN, O. PITIOT, P. VERNET J. DREVET
}

Université Blaise Pascal-Clermont 2, UMR-CNRS 6547, Equipe "Epididyme et Maturation des Gamètes", Aubière

Chez les mammifères, l'épithélium épididymaire, via ses activités de sécrétion et de réabsorption, participe à la maturation post-testiculaire des spermatozoïdes en créant un environnement luminal particulier, tout au long du trajet épididymaire. GPX5, gène modèle du laboratoire, code pour une protéine appartenant à la famille des glutathion peroxydases. Sécrétée dans la lumière de l'épididyme, on la retrouve également liée à la région acrosomique des spermatozoïdes. D'expression tardive, GPX5 est considéré comme un marqueur terminal de la différenciation épididymaire.

Dans cette étude, nous nous sommes attachés à analyser in vivo, chez la souris, l'expression différentielle du gène GPX5, par RT-PCR et western-blot. De ce travail, il ressort que le gène murin simple copie GPX5 présente un profil d'expression complexe donnant naissance à au moins deux messagers et trois protéines, dont les distributions cellulaires et tissulaires sont distinctes.
L'analyse des mécanismes impliqués montre que ces populations nucléiques et protéiques sont à la fois le résultat d'événements post-transcriptionnels (épissage alternatif) et post-traductionnels (O-glycosylations). 


\title{
Recherche d'antigènes spermatiques pour la mise au point d'un vaccin contraceptif visant à limiter les pullulations du campagnol terrestre (Arvicola terrestris)
}

\author{
E. GRIGNARD, P. VERNET, J. DREVET
}

Université Blaise Pascal-Clermont 2, CNRS UMR6547, Equipe Epididyme et Maturation des Gamètes, Aubière

Le campagnol terrestre Arvicola terrestris est un rongeur fouisseur, vivant dans les prairies des régions de moyenne montagne, où il provoque d'importantes pertes dans la production de fourrage. Depuis environ trente ans, le seul moyen de lutte contre sa pullulation consiste en l'empoisonnement des animaux par un anticoagulant chimique disposé sur des appâts. En alternative à cet empoisonnement (non spécifique), nous travaillons à l'élaboration d'un vaccin contraceptif ciblé sur Arvicola terrestris.

Nous avons dans un premier temps produit des anticorps dirigés contre des protéines spermatiques, en immunisant des lapins avec des spermatozoïdes entiers prélevés au niveau de la queue de l'épididyme (organe de maturation des spermatozoïdes). Par immunohistochimie, nous avons vérifié que ces anticorps reconnaissaient des protéines spermatiques. Ces protéines sont localisées sur l'acrosome et la gouttelette cytoplasmique.
Ces anticorps ont ensuite été utilisés pour identifier les protéines reconnues à partir d'une électrophorèse bidimensionnelle. Les protéines reconnues ont été identifiées par spectrométrie de masse. L'utilisation d'oligonucléotides dégénérés nous a permis d'obtenir les ADN spécifiques d'Arvicola terrestris. Ces ADN ont été séquencés, et leur traduction conceptuelle effectuée. Ces séquences primaires vont être comparées à leurs orthologues afin de déterminer quels peptides pourraient être utilisés pour une immunocontraception du campagnol terrestre, en étudiant leurs critères de spécificité et d'immunogénicité. 


\title{
Gènes cibles des LXRs (Liver X Receptors) dans l'épididy- me murin : étude in vitro sur un modèle cellulaire
}

\author{
A. KOCER, F. SAEZ, A. BRITAN, E. GRIGNARD, J. LOBACCARO, J. DREVET
}

Université Blaise Pascal - Clermont 2, CNRS UMR6547, Equipe "Epididyme et maturation des gamètes", Aubière

Les récepteurs nucléaires aux oxystérols "Liver $X$ Receptors" (LXRs) sont impliqués dans l'homéostasie du cholestérol et le métabolisme lipidique. Les souris mâles déficientes pour les 2 isoformes des LXR ( $\alpha$ et $\beta$ ) présentent une perturbation sévère de la structure de l'épithélium des segments 1 et 2 de la tête de l'épididyme ainsi qu'une fragilité des spermatozoïdes. Ces altercations engendrent une stérilité chez les souris mâles.

Une lignée cellulaire issue de la tête de l'épididyme murin (cellule B2) et développée au laboratoire a été utilisée dans cette étude. La présence de $L X R \alpha$ dans ces cellules a été mise en évidence par immunocytochimie et la fonctionnalité des LXRs a été vérifiée par la capacité de réponse des cellules $\mathrm{B} 2$ à un agoniste synthétique de ces récepteurs, le T0901317 (T09). La recherche de gènes cibles potentiels a été effectuée par des analyses protéomiques en électrophorèse bidimensionnelle sur les cellules B2 stimulées par le T09. Huit protéines régulées positivement par les $L X R s$ ont été isolées. Une seule a pu être identifiée par spectrométrie de masse : la polyubiquitine, dont l'implication dans l'homéostasie cellulaire du cholestérol a déjà été rapportée. 


\title{
Inhibine B plasmatique, marqueur des tumeurs testiculaires à cellules de Leydig
}

\author{
C. DUPARC, H. LEFEBVRE, J.M. KUHN \\ Service d'Endocrinologie, Diabète et Maladies Métaboliques, Centre d'Investigation Clinique INSERM 204, \\ CHU Rouen et INSERM U413, Université de Rouen
}

Les tumeurs testiculaires à cellules de Leydig (TTL) se développent à partir des cellules interstitielles stéroïdogènes. Alors qu'une moitié d'entre elles est silencieuse sur le plan endocrinien, une TTL sur deux de l'homme adulte est responsable d'une sécrétion excessive d'estrogènes. Le profil hormonal associe alors élévation relative ou absolue du taux plasmatique d'estradiol (E2) et réduction plus ou moins profonde de la testostéronémie. Cette dernière est la conséquence de la freination de la sécrétion gonadotrope par l'E2 d'origine tumorale. Paradoxalement, l'effet freinateur de la sécrétion tumorale apparaît plus marqué sur la FSH que sur la LH. Cette dissociation LH-FSH s'observe aussi bien sur les taux plasmatiques de base que sur les réponses à l'administration aigüe de $100 \mu \mathrm{g}$ de $\mathrm{GnRH}$. Ceci suggère que la tumeur sécrète non seulement de I'E2 mais puisse également être source d'inhibine $B$, médiateur physiologique essentiel du rétro-controle gonadique sur la sécrétion de FSH. Pour vérifier cette hypothèse, les taux plasmatiques d'inhibine $B$ ont été mesurés dans 11 cas de TTL estrogéno-sécrétrices, confirmées par l'examen anatomopathologique. L'estradiolémie a été mesurée par immunoluminescence (Immulite 2000, DPC) et les taux de gonadotrophines plasmatiques par méthodes immunoradiométriques (FSH et LH Assays, Amerlite). Une méthode sandwich (Inhibin B-Dimer Assay, Serotec) a permis de déterminer le taux plasmatique d'inhibine $B$. Au moment du diagnostic, l'estradiolémie moyenne est de $66+/-8 \mathrm{pg} / \mathrm{ml}$. Le taux plasmatique d'inhibine $B$ est élevé dans 7 cas sur 11 . Les valeurs moyennes respectives de FSH et d'inhibine $B$ sont de 1,6+/-0,3 U/I $(\mathrm{N}=)$ et $501+/-72$ $\mathrm{pg} / \mathrm{ml}$ pour des normes respectives chez l'homme adulte $(N=84)$ comprises entre 0,5 et 5 d'une part, 100 et 320 d'autre part. FSH et inhibine $B$ sont négativement corrélés en pré-opératoire $(R=0,78, p<0,01)$, lien statistique qui disparaît en post-opératoire. Après tumorectomie, le taux d'inhibine B s'abaisse et s'inscrit dans les limites de la normale de l'homme adulte. Dans cette série, $70 \%$ des TTL sécrètent à la fois E2 et inhibine $B$. Cette co-sécrétion explique le profil particulier d'inhibition de la fonction gonadotrope, plus marquée sur la FSH que sur la $\mathrm{LH}$. Le taux d'inhibine $\mathrm{B}$ plasmatique, déterminable en routine, pourrait représenter un marqueur de diagnostic et de suivi des TTL de l'homme adulte. 


\title{
Taux de fragmentation de l'ADN des spermatozoïdes: mise au point d'une technique, valeur diagnostique et pronostique
}

\author{
F. BRAYOTEL ${ }^{1}$, F. VIALARD ${ }^{1}$, M. ALBERT ${ }^{1}$, V. DELABROYE ${ }^{1}$, C. SABBAGH $^{1}$, \\ N. LEDEE-BATAILLE 2 , J. SELVA 1 \\ 1 Service d'Histologie, Embryologie, Cytogénétique, Biologie de la Reproduction et Génétique Médicale. CHI Pois- \\ sy-St Germain, Poissy ; 2 Service de Gynécologie Obstétrique. CHI Poissy-St Germain, Poissy
}

\section{BUT}

L'étude de l'intégrité nucléaire du spermatozoïde suscite de nouveaux travaux dans le but de mieux appréhender les capacités de fécondance des spermatozoïdes et de tenter d'expliquer certains échecs des techniques d'AMP. Nous avons cherché à définir des groupes de patients à risque accru de taux élevé de fragmentation de I'ADN spermatique et pris en charge en AMP.

\section{MATERIELS ET METHODES}

Nous avons étudié systématiquement 101 échantillons de sperme provenant de patients consultant préalablement à leur inclusion dans un protocole d'AMP. Nous avons choisi la méthode Tunel in situ, avec lecture au microscope à fluorescence et utilisé le kit Roche. Nous avons mis au point une méthode de fixation permettant de réaliser à partir d'une même préparation, l'étude de la fragmentation de l'ADN spermatique et l'évaluation par FISH du taux d'aneuploïdie des spermatozoïdes.

\section{RESULTATS}

Dans la cohorte étudiée, la répartition de l'indice de fragmentation était gaussienne avec une moyenne de $5,8 \%$ et une valeur seuil, fixée en fonction de la valeur de la médiane, à $9 \%$. Globalement, le taux de fragmentation était retrouvé corrélé de manière significative et inverse avec la concentration spermatique, ainsi qu'avec la mobilité progressive $(a+b)$.

Les deux groupes de patients inclus en ICSI pour indication masculine pure et les patients inclus dans un protoco- le "échec d'implantation" (plus de 10 embryons transférés sans grossesse) ont pu alors être considérés comme "groupes à risque d'apoptose spermatique", leurs résultats étant significativement supérieurs à ceux des autres groupes. Quant aux potentielles valeurs prédictives positive et négative de ce paramètre, les grossesses obtenues parmi ces couples nous conduisent à rester très prudents. II ne parait pas possible de déterminer actuellement un taux d'apoptose au-delà duquel aucune grossesse ne serait obtenue.

\section{CONCLUSION}

Cette étude serait à préconiser préférentiellement chez 3 groupes de patients :

- les patients en échec d'implantation et ayant dans leurs antécédents des fausses couches spontanées ;

- les patients possédant dans leurs habitus des facteurs connus favorisant l'apoptose ;

- tous les patients pris en charge en ICSI.

Cette information pourrait être importante pour le conseil aux patients si un facteur favorisant la fragmentation était mis en évidence et pour la réalisation de l'ICSI elle-même. En effet, dans les situations d'ICSI avec un taux élevé de fragmentation de I'ADN spermatique, la sélection des spermatozoïdes à injecter en fonction des caractéristiques morphologiques de leur noyau pourrait peut-être permettre de diminuer le risque d'injecter un spermatozoïde à ADN fragmenté et d' améliorer les résultats de l'ICSI. 


\title{
Syndrome de Klinefelter et infertilité
}

\author{
A. BAHLOUL ${ }^{1}$, N. ABDELMOULA-BOUAYED ${ }^{2}$, A. MALLEK ${ }^{1}$, Y. MHADHEB ${ }^{1}$, T. REBAI ${ }^{2}$, \\ M.N. MHIRI 1 \\ 1 Service d'Urologie CHU Habib Bourguiba ; 2 Laboratoire d'histologie, Faculté de médecine de Sfax, Tunisie
}

\section{BUT}

Le syndrome de Klinefelter est une entité clinique définie par la présence chez des sujets de phénotype masculin d'un chromosome $X$ supplémentaire; elle serait la plus fréquente des anomalies des chromosomes sexuels. Le but de ce travail est de rapporter les caractéristiques diagnostiques, pronostiques et thérapeutiques de l'infertilité au cours de cette pathologie.

\section{MATERIEL ET METHODES}

9 hommes atteints d'un syndrome de Klinefelter, diagnostiqués par l'étude cytogénétique moléculaire par FISH sur lymphocytes sanguins, ont été découvert parmi les 152 hommes consultants pour infertilité dans le cadre de l'unité de recherche de santé US 17 durant une période de 2 ans (2001-2003). Pour chaque patient nous avons réalisé un spermogramme, un bilan hormonal (FSH, LH, testostérone, prolactine), une biopsie testiculaire, un caryotype sanguin et l'étude de la chromatine sexuelle.

\section{RESULTATS}

La fréquence de cette pathologie est de $6 \%$ des hommes consultant pour infertilité, $56,2 \%$ des anomalies chromosomiques révélées chez les hommes infertiles, $17,3 \%$ des hommes présentant une azoospermie ou oligospermie et $50 \%$ des hommes présentant une azoospermie sécrétoire. L'âge moyen au moment du diagnostic était de 34 ans (27-47). L'atrophie testiculaire était constante; elle était bilatérale ( 8 cas) et unilatérale (1 cas) contrastant avec une normalité des organes génitaux externes. La gynécomastie était observée dans 2 cas $(22,2 \%)$. Les signes d'hypogonadisme étaient présents dans $78 \%$. L'hypotestostéronémie était notée chez 7 patients. Le taux de FSH était élevé chez tous les patients témoignant d'hypogona- disme hypogonadotrope. L'azoospermie était constante. La biopsie testiculaire pratiquée chez 5 patients a montré l'absence de cellules germinales et des tubes séminifères hypoplasiques. Le test de Barr était positif dans tous les cas en faveur de la présence d'un chromosome $X$ supplémentaire. Le caryotype a montré un statut cytogénétique homogène $47, X X Y$ ( 8 cas) et en mosaïque (1 cas). Tous les patients ont bénéficié d'une androgénothérapie substitutive afin d'améliorer le développement des caractères sexuels secondaires et la sexualité et de prévenir l'ostéoporose. aucun patient n'a eu recours à la procréation médicalement assistée étant donné l'azoospermie, le statut cytogénétique homogène et les résultats de la biopsie testiculaire.

\section{CONCLUSION}

Le pronostic de fertilité chez l'homme porteur de syndrome de Klinefelter ne serait pas pour certains auteurs aussi sombre qu'on le croyait. Et bien que le nombre des cas pour lesquels une PMA soit possible est réduit, il importe de recourir à tous les moyens pour pouvoir procréer. 


\title{
La détermination du taux d'aneuploïdie dans les spermatozoïdes peut-elle constituer un test prédictif avant I'ICSCI?
}

\author{
F. PETIT ${ }^{1}$, N. FRYDMAN¹, M. BENKHALIFA 1 , A. LE DU ${ }^{1}$, A. ABOURA, R. FANCHIN², R. FRYFMAN², \\ G. TACHDJIAN 1
}

1 Service d'Histologie-Embryologie-Cytogénétique ; 2 Service de Gynécologie-Obstétrique et Médecine de la Reproduction, Hôpital Antoine Béclère, Clamart

\section{INTRODUCTION}

Les anomalies chromosomiques embryonnaires sont une des principales causes des échecs d'implantation et de développement. Des échecs d'implantation sont observés après ICSI chez des couples ayant des caryotypes sanguins normaux. Dans le but de déterminer les patients à risque d'échecs d'ICSI et la validité de l'analyse cytogénétique des spermatozoïde, nous avons déterminé les taux d'aneuploïdie dans les spermatozoïdes de patients inclus dans un programme d'ICSI.

\section{MATERIELS ET METHODES}

Dix neuf patients ICSI ont été étudiés. Dix patients avaient eu au moins 4 tentatives d'ICSI sans obtenir de grossesse (groupe A). Neuf patients avaient obtenu une grossesse après 1 à 3 tentatives d'ICSI (groupe B). Dix hommes fertiles avec des paramètres spermatiques normaux ont été étudiés comme témoins (groupe $\mathrm{C}$ ). L'analyse cytogénétique des noyaux spermatiques a été réalisé in situ fluorescente $(\mathrm{FISH})$ à l'aide de sondes spécifiques des chromosomes 8, 9, 13, 18, 21, $X$ et $Y$.

\section{RESULTATS}

Les taux d'aneuploïdie pour chaque chromosome étudié et le taux de diploïdie étaient significativement augmentés dans les groupes A et B par rapport au groupe $C(p<0,05)$. Pour les patients des groupes $A$ et $B$, les variations interindividuelles des taux d'aneuploïdie ne permettaient pas de déterminer de différence significative pour chaque chromosome. Nous avons été amené à considérer l'aneuploïdie totale représentant la somme des aneuploïdies pour chacun des chromosomes étudiés. Ainsi, l'aneuploïdie totale est non seulement augmentée dans les groupes A et $B$ par rapport au groupe C mais également dans le groupe A par rapport au groupe B $(p<0,0001)$. Ce profil chromosomique spermatique est indépendant des paramètres classiques du spermogramme.

\section{CONCLUSION}

Le profil chromosomique spermatique semble pouvoir être utiliser comme test prédictif en préalable à I'ICSI de manière à établir un conseil génétique adaptée aux patientsoligo-asthéno-tératozoospermiques. 


\title{
Corrélation entre le nombre d'anomalies chromosomiques et l'importance de l'oligospermie
}

\author{
M. DEMAILLY ${ }^{1}$, S. FLORET ${ }^{2}$, R. MEENS ${ }^{2}$, J. GEKAS ${ }^{2}$, P. MERVIEL ${ }^{2}$, J. PETIT ${ }^{1}$ \\ 1 Service d'Urologie-Transplantation, CHU Amiens ; 2 Service de Biologie de la reproduction et de Cytogénétique, \\ CHU Amiens
}

Il est bien établi dans la littérature que l'homme infertile représente une population à risque de présenter une anomalie chromosomique (AC). Leur prévalence est considéré comme inversement proportionnelle aux nombres de spermatozoïdes au spermogramme (Chandley, 1979). Depuis l'apparition récente de l'ICSI, la prévalence des AC chez les hommes pris en charge par cette technique demande à être mieux connue.

Pour mieux définir la fréquence de ces $A C$ chez les hommes infertiles, nous avons réalisé une étude multicentrique nationale rétrospective du caryotype de 2196 hommes inclus dans des protocoles ICSI en France. L'infertilité a été évaluée systématiquement par un examen clinique avec mesure du volume testiculaire, par un dosage de la FSH et un spermogramme.

Dans notre étude, un taux global de $6,19 \%$ d'AC a été retrouvé quelque soit le type d'infertilité. Il existe une différence significative $(p=0.0016)$ entre les patients présentant une oligospermie entre 0 et 2 millions de spermatozoïdes par $\mathrm{ml}$ et ceux dont la numération est supérieur à 2 millions, respectivement $5,21 \%$ versus $2,09 \%$. Par contre, il n'existe pas de différence significative $(p=0,17)$ entre le groupe avec une oligospermie comprise entre 2 et 20 millions de spermatozoïdes par $\mathrm{ml}$ et le groupe dont le spermogramme est normal, à savoir $2,09 \%$ versus $3,46 \%$.

Notre étude confirme que la fréquence des $A C$ est inversement proportionnelle à la numération des spermatozoïdes mais jusqu'à un seuil de 2 millions par $\mathrm{ml}$ au-delà duquel le risque d'AC varie peu, même pour des spermogrammes dont la numération est normale. 


\title{
Etude de deux marqueurs de l'apopstose et de la ségrégation méïotique sur des spermes de patients porteurs de translocation chromosomique
}

\author{
F. BRUGNON1, E. VAN ASSCHEV 2 , B. SIONS 1 , L. JANNY 1 , B. AUBLET-CUVELLIER ${ }^{3}$, \\ I. LIEBAERS ${ }^{2}$, A. VAN STEIRTEGHEM ${ }^{2}$, D. BOUCHER ${ }^{1}$ \\ 1 Laboratoire de Biologie de la reproduction, $\mathrm{CHU}$, Clermont-Ferrand, France ; 2 Laboratoire de Biologie de la \\ reproduction, AZVUB, Bruxelles, Belgique ; 3 Département d'épidémiologie, $\mathrm{CHU}$, Clermont Ferrand, France
}

\section{INTRODUCTION}

La prévalence des patients présentant une translocation chromosomique réciproque ou Robertsonienne au sein des hommes infertiles est importante. Pour tenter d'expliquer la physiopathologie de l'infertilité de ces patients, nous avons mesuré l'expression de deux marqueurs apoptotiques et la ségrégation méiotique des spermatozoïdes présents dans l'éjaculat de ces sujets, comparés à une population contrôle de spermes de donneurs. Ce travail n'a jamais été réalisé chez l'Homme.

\section{MATERIEL ET METHODES}

Les paramètres spermiologiques standards (OMS, 1999) ont été mesurés pour l'ensemble des spermes (donneurs $n=20$; translocation réciproque $n=14$; translocation Robertsonienne $n=6$ ). Deux marqueurs d'apoptose ont été analysés : l'un membranaire (externalisation de la phosphatidylsérine (PS), par la technique annexine $V$ ), l'autre nucléaire (fragmentation de l'ADN, par la technique TUNEL (TdT-mediated dUTP-biotin Nick End Labelling)). L'étude de la ségrégation méiotique a été effectuée par technique FISH (Fluorescence In Situ Hybridation). En fonction de la quantité initiale de spermatozoïdes mesurée, les différentes techniques de mesures ont été appliquées (mesures annexine $V \pm T U N E L \pm F I S H$ ). Les analyses de comparaison ont été effectuées par un test non paramétrique $U$ de Mann et Whitney ; et les corrélations par un test non paramétrique de Spearman à l'aide du logiciel Stat View 5 (SAS Institute, 1998) $(p<0,05)$.

Résultats : Les spermes des patients porteurs d'une translocation chromosomique présentent des paramètres spermiologiques altérés et significativement différents de la population contrôle.

La proportion de spermatozoïdes ayant externalisé la PS dans les spermes des patients étudiés (41\%-96\%) présentant une translocation chromosomique est significativement plus élevée, comparée à la population contrôle (6\%-53\%). De plus, le pourcentage de spermatozoïdes présentant une fragmentation de l'ADN est significativement plus important dans les spermes des patients (10$30 \%)$, comparée à la population contrôle $(8-10 \%)$.

Enfin, nos résultats montrent des taux de gamètes porteurs d'un déséquilibre chromosomique inférieurs aux valeurs attendus. Le type de ségrégation méiotique alterne est observé le plus fréquemment dans les spermes de patients porteurs d'une translocation réciproque (33\%$58 \%$ ) et Robertsonienne (76-88\%).

\section{CONCLUSION}

Nos résultats suggèrent la probable existence d'un phénomène biologique contribuant à l'élimination des gamètes porteurs d'un déséquilibre chromosomique et pouvant expliquer les altérations des paramètres spermiologiques. Les mécanismes de mort cellulaire programmée du spermatozoïde humain étant encore peu connus, il serait intéressant de confirmer leurs implications dans la physiopathologie de l'infertilité de ces patients par l'étude de marqueurs spécifiques de l'apoptose (Fas, variation du potentiel membranaire mitochondrial, PRY ...) et l'analyse de le mise en jeu des processus d'apoptose au niveau de la spermatogenèse. 


\title{
Le risque chromosomique pour un patient porteur d'une translocation $t(X ; 2)$ concerne non seulement la translocation mais aussi la ségrégation
}

\author{
F. VIALARD ${ }^{1}$, B. GUTHAUSER ${ }^{3}$, M. BAILLY², M. BERGERE 1 , D. MOLINA-GOMES ${ }^{1}$, M. DOLLEY4, \\ M. ALBERT ${ }^{1}$, J. SELVA ${ }^{1}$
}

1 Service d'Histologie-Embryologie-Cytogénétique, Biologie de la Reproduction et Génétique Médicale. CHI Poissy-Saint Germain, Poissy ; 2 Service de Gynécologie Obstétrique. CHI Poissy-Saint Germain, Poissy ; 3 Service de Biologie de la Reproduction, CHG Dreux, Dreux ; 4 Service de Gynécologie Obstétrique. CHG Dreux, Dreux

Chez un homme, les translocations impliquant les gonosomes sont le plus souvent responsables d'azoospermie ou parfois d'oligospermie, conduisant les patients à demander une AMP. Nous rapportons ici le cas d'un patient oligosperme, porteur d'une transiocation $(X ; 2)$ et les modalités spécifiques du conseil génétique énoncé à ce couple avant ICSI.

Monsieur $C$ et sa conjointe âgée de 42 ans consultent pour infertilité primaire de 2 ans. Le spermogramme montre une oligospermie variable allant de 0,5 à $5 \mathrm{M} / \mathrm{ml}$, associée à une asthénospermie modérée $(a+b=40 \%)$ et une tératospermie ( $20 \%$ normaux). L'examen clinique était normal ainsi que les dosages hormonaux $(\mathrm{FSH}=5 \mathrm{UI} / \mathrm{l}$, Testostérone $=5,3 \mathrm{ng} / \mathrm{ml}$ ). Le caryotype a montré une translocation $46, Y t(X ; 2)(p 21 ; q 25.3)$. L'ensemble de ces résultats nous a conduit, après un conseil génétique, à proposer une exploration des spermatozoïdes par FISH pour connaître le mode de ségrégation de la translocation et le risque pour la descendance.

Les déséquilibres méiotiques directement liés à la translocation ont été étudiés en utilisant 4 sondes marquant les centromères des chromosomes $2, X$ et $Y$ et les télomères de la région du bras court du chromosome 2. Cette étude a montré la présence de $34 \%$ de spermatozoïdes normaux ou équilibrés pour les chromosomes étudiés, et $76 \%$ de spermatozoïdes présentant un déséquilibre lié à la translocation et/ou des anomalies de non-disjonction des gonosomes. Devant ce résultat il a été décidé de pratiquer une nouvelle étude en $\mathrm{FISH}$, de manière à préciser les risques éventuellement accrus de non-disjonction des chromosomes $X$ et $Y$. Effectivement sur 225 spermatozoïdes seulement $54 \%$ étaient normaux.

Il existe donc non seulement un risque de déséquilibre lié à la translocation pour le conceptus mais également celui d'un syndrome de Klinefelter ou Turner par malségréga- tion des chromosomes sexuels. Globalement, la probabilité d'obtenir un embryon normal était de $25 \%$.

Suite à ce résultat et en raison de l'âge de la conjointe, nous avons déconseillé I'ICSI au couple au cours d'un nouveau conseil génétique.

Ce cas souligne l'intérêt de pratiquer l'analyse par FISH des conséquences d'une translocation dans les spermatozoïdes d'un patient porteur. L'étude ne doit pas se limiter à l'étude de la translocation elle-même, mais également concerner les anomalies de non-disjonction des gonosomes, fréquentes au cours de la spermatogenèse et plus particulièrement en présence d'une translocation impliquant un gonosome. 


\title{
Chromosome Y dicentrique
}

\author{
A. BAHLOUL, Y. MHADHEB, A. MALLEK, N. REBAI, A. SAHNOUN, H. KETAT, M.N. MHIRI
}

Service Urologie CHU Bourguiba, Sfax, Tunisie

\section{INTRODUCTION}

Les chromosomes dyscentriques sont très rares, ils constituent les remaniements de structure les plus fréquent du chromosomes $Y$. Ils ont des conséquences phénotypiques très variables.

\section{OBSERVATIONS}

Nous nous rapportons l'observation originale d'un patient de morphotype masculin qui s'est présenté pour retad staturo-pondéral sans signes dysmorphiques, il est porteur d'une ambiguïté sexuelle (stade $v$ de prader) avec micropenis, un hypospdias périnal vulviforme, une incurvation de la verge, et des bourses avec un aspect de grande lèvre soudée et une ectopie testiculaire bilatérale (agénésie gonadique gauche en per-operatoire). La testosteronemie indétectable, la $\mathrm{FSH}$ normale et la $\mathrm{LH}$ légèrement abaissé.

L'étude cytogénétique utilisant les différentes approches conventionnelles, de banding, et moléculaire ont permis de rattacher ce tableau de dysgénésie gonadique à la présence d'un dyscentrique du bras long du chromosome $Y$ en mosaïque, à la localisation de ces points de cassure et à la confirmation de la présence de certains loci spécifiques et critiques du chromosome $Y$.

Une évaluation d'ordre anatomique des OGE avait révélé les bonnes dimensions des corps caverneux et la possibi- lité d'une reconstruction urétrale satisfaisante ce qui a permis, alors une correction dans le sens masculin. L'examen histologique du testicule droit enlevé a permis d'établir le diagnostic de dysgénésie gonadique mixte orienté vers le sens masculin, un traitement à base d'androgénothérapie a été instauré.

\section{CONCLUSION}

II s'agit d'une affection très rare dont la corrélation objective entre génotype et phénotype n'est pas encore évidente, il est important d'approfondir l'analyse du chromosome discentrique. 


\title{
Etude par FISH de cellules somatiques et germinales du tissu testiculaire de deux hommes porteurs de chromosome $\mathrm{Y}$ pseudo dicentrique
}

\author{
B. SCHUBERT ${ }^{1}$, C. GOUMY ${ }^{2}$, G. LACROUTE ${ }^{2}$, P. VAGO ${ }^{2}$, L. JANNY ${ }^{1}$, D. BOUCHER ${ }^{1}$, A. GENEIX ${ }^{2}$ \\ 1 Laboratoire de Biologie du Développement et de la Reproduction, CHU de Clermont-Ferrand ; 2 Laboratoire de \\ Cytogénétique, Faculté de Médecine PI H. Dunant 63000 Clermont-Ferrand
}

\section{INTRODUCTION}

Bien que rare, le chromosome $Y$ pseudo dicentrique est l'anomalie de structure la plus fréquente des gonosomes. L'analyse du tissu testiculaire est rarement rapportée.

Nous rapportons ici l'étude par FISH du tissu testiculaire de deux patients porteurs du caryotype somatique suivant: $45, \mathrm{X0} / 46, \mathrm{X}$,psu $\operatorname{dic}(Y)$ (pter $\rightarrow \mathrm{q} 11:: \mathrm{q} 11 \rightarrow$ pter).

\section{MATERIEL ET METHODES}

Ces 2 patients ont consulté dans notre centre pour une infertilité primaire. Ils sont âgès de 31 ans et plusieurs spermogrammes ont retrouvé une azoospermie.

Un caryotype standard a été réalisé chez chacun de ces deux patients sur sang périphérique. Une étude complémentaire par FISH sur sang périphérique avec une sonde pour chacun des deux gonosomes (SRY et CEPX) a confirmé ces premiers résultats. Sur le tissu testiculaire, une 3ième sonde a été utilisée (CEP 18) pour évaluer la ploïdie de la cellule analysée.
Une étude de la région $A Z F$ du chromosome $Y$ a été effectuée par biologie moléculaire.

\section{RESULTATS (Tableau) \\ CONCLUSION}

Dans le tissu testiculaire toutes les cellules estimées haploïdes portent un chromosome $X$ et aucune cellule haploïde porteuse du seul chromosome $Y$ remanié n'a été observée. Malgré de rares images méiotiques, la proportion de cellules haploïdes n'est pas négligeable. La méiose est donc difficile mais possible. La présence du chromosome $Y$ remanié semble jouer un rôle important dans ce blocage puisque la quantité de cellules haploïdes porteuses de ce chromosome est relativement faible. Une hypothèse peut être que la présence d'un excès de chromosome $Y$ conduise à l'exclusion de l'un de ces chromosomes, comme cela est évoqué chez les hommes $47, \mathrm{XYY}$. Dans notre étude, ces "2" chromosomes étant liés, ce mécanisme aboutirait à l'exclusion de la totalité du chromosome $Y$ remanié.

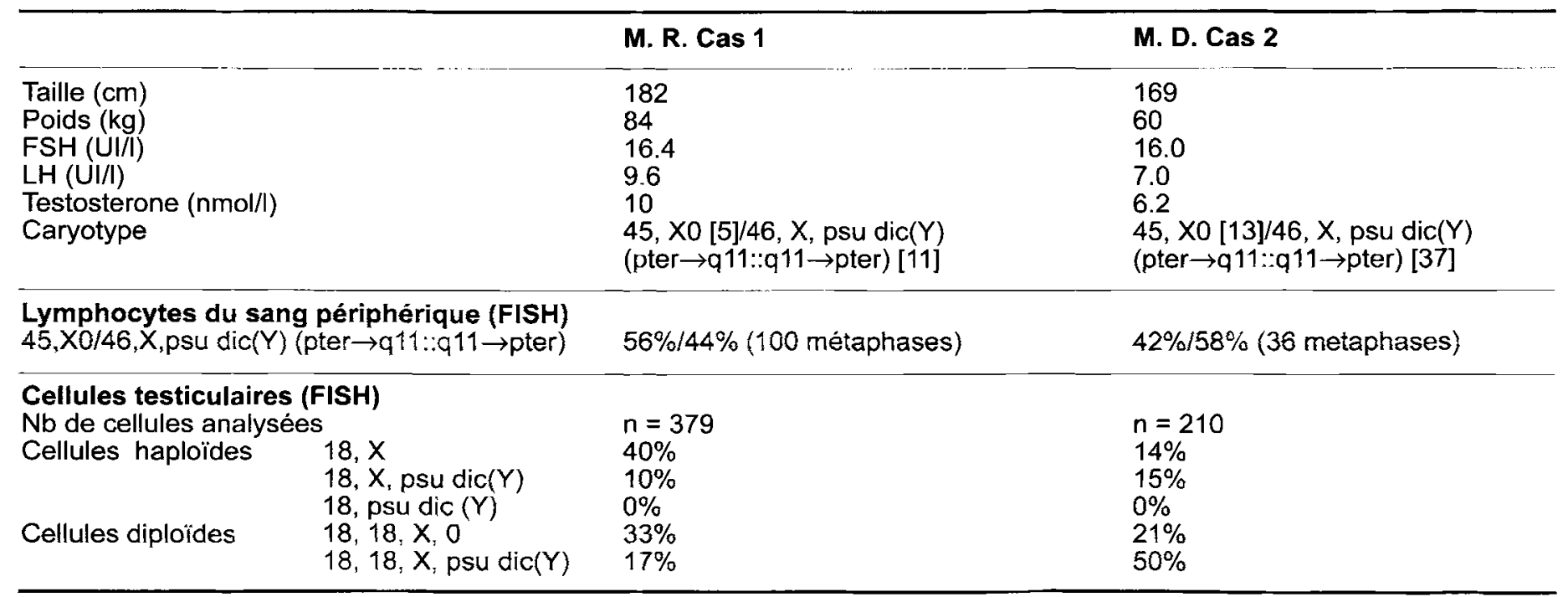

La délétion des régions $A Z F b$ et $A Z F c$ a été retrouvée chez ces 2 patients. 


\title{
Recherche des microdélétions du bras long du chromosome $Y$ chez des hommes infertiles
}

\author{
S. IBALA, M. AJINA, M. GRIBAA, H. ELGHZEL, A. AMOURI, M. AJINA-ZAOUALI, A. SAAD
}

Service de Cytogénétique et de Biologie de la Reproduction. CHU Farhat HACHED, Sousse, Tunisie

\section{INTRODUCTION}

Depuis la construction de la première carte génétique du chromosome $\mathrm{Y}$, la recherche de microdélétions sur ce chromosome est devenue possible et a permis de détecter des anomalies non visibles en cytogénétique classique.

Les travaux de Vogt ont permis de dénombrer trois zones particulièrement soumises aux microdélétions chez les azoospermiques et les oligozoospermiques extrêmes et sévères à savoir : $A Z F a, A Z F b$ et $A Z F c$.

Notre étude consiste à évaluer la prévalence des microdélétions du bras long du chromosome $Y$ en étudiant une population tunisienne d'hommes infertiles.

\section{MATERIEL ET METHODES}

Cent quinze patients atteints d'azoospermie ou d'oligozoospermie idiopathiques ont été retenus dans notre travail.

Pour l'analyse génétique, les microdélétions du bras long du chromosome $Y$ ont été recherchés par PCR multiplex des marqueurs génomiques STS situés dans les trois régions $A Z F$, suivie de l'électrophorèse du produit de PCR sur gel d'agarose.

\section{RESULTATS ET DISCUSSION}

Trois patients sur les 115 ont montré une microdélétion du bras long du chromosome $Y$ ce qui correspond à une fréquence de $2,6 \%$. Ces microdélétions ont toutes concerné la zone AZFc. Deux des 3 patients porteurs de microdélétions sont azoospermiques $(2 / 58=3,4 \%)$ alors que le troisième est oligozoospermique extrême $(1 / 42=2,3 \%)$.

La fréquence et la localisation de ces microdélétions varient considérablement selon les études. Ces variations traduisent essentiellement la variabilité génétique entre les populations.

\section{CONCLUSION}

La découverte d'une microdélétion du bras long du chromosome $Y$ permet, d'une part d'attribuer aux azoospermiques et aux oligozoospermiques extrêmes et sévères une cause à leur infertilité et d'arrêter toute investigation ultérieure, et d'autre part de décider de la technique d'assistance médicale à la procréation adéquate. 


\title{
Comparaison de deux kits de détection des microdélétions du chromosome $Y$
}

\author{
I. AKNIN-SEIFER, R. TOURAINE, H. LEJEUNE, F. FELLMANN, C. JIMENEZ, A.K. FAURE, \\ J. CHOUTEAU, R. LEVY \\ Laboratoire de Biologie de la Reproduction, $\mathrm{CHU}$ de Saint-Etienne
}

\section{INTRODUCTION}

En cas de troubles sévères de la spermatogenèse, la recherche des microdélétions du chromosome $Y$ est fortement conseillée avant ICSI. Lors d'une étude préliminaire, nous avons comparé une technique "maison" adaptée des recommandations européennes (a) à la première version du kit PROMEGA ( $Y$ Deletion Detection System 1.1 (b)). Une enquête récente a permis d'observer que la majorité des laboratoires français utilisent des techniques maison pour cette recherche (c). Le but de ce travail est de valider deux récents kits : la nouvelle version "Y chromosome deletion detection system 2.0" du kit PROMEGA et le kit italien BIRD-SET Kits (Y Chromosome UE and Y Chromosome extension).

\section{MATERIEL ET METHODES}

12 microdélétions du chromosome $Y$ identifiées au préalable en utilisant 26 STS (Sequence Tagged Sites) : deux en $A Z F a$, deux en $A Z F b$, quatre en $A Z F b+c$, trois en $A Z F c$, et une $A Z F a+b+c$. Nous avons testé la nouvelle version du kit PROMEGA " $Y$ chromosome deletion detection system 2.0" (modifiée selon les recommandations européennes de l'EAA) et les deux kits italiens BIRD-SET (une première étape de détection " $Y$ Chromosome UE" avec 8 STSs et une seconde étape pour préciser la taille de la délétion, "Y Chromosome extension"). Les produits de PCR ont été analysés par électrophorèse avec un bioanalyseur (AGILENT TECHNOLOGIES $\odot$ ).

\section{RESULTATS}

Les deux kits commerciaux ont confirmé les 12 délétions et permis d'en déterminer avec précision l'étendue, avec cependant quelques différences. La nouvelle version du kit PROMEGA 2.0 a été améliorée, avec l'ajout de deux marqueurs essentiels, spécifiques de la région AZFa, (sY86, sY84), et la suppression de deux des marqueurs superflus (sY239, sY153) : certains STS superflus demeurent cependant présents dans le kit (sY133). Enfin, de nombreuses bandes parasites non spécifiques ont pu être observées dans la plupart des électrophorèses des produits de PCR du kit Promega.

\section{CONCLUSION}

Les avantages (standardisation, mix préparés) et les inconvénients (coût, nombre de PCR et électrophorèses) des deux kits seront présentés. Ces deux kits récemment commercialisés, basés sur deux stratégies différentes, offrent un confort d'utilisation dans la recherche des microdélétions du chromosome $Y$ en routine. Les deux kits doivent maintenant être validés dans des conditions de routine, avec des échantillons négatifs et des contrôles fertiles normospermiques.

\section{REFERENCES}

1. SIMONI ET AL : International Journal of Andrology, 1999,22 :292-299

2. AKNIN-SEIFER ET AL. : Human Reproduction, 2003 Feb; 18(2): 257-61.

3. AKNIN-SEIFER ET AL. : Human Reproduction, 2004 Apr;19(4):788-93. 


\title{
Intérêt de la DHPLC dans la mise en évidence des copies de DAZ
}

\author{
B. DUCROCQ, I. AKIN-SEIFER, R. TOURAINE, S. FERNANDES, K. MCELREAVEY, J.P. SIFFROI, H. \\ LEJEUNE, F. FELLMANN, C. JIMENES, A.K. FAURE, J. CHOUTEAU, R. LEVY
}

Laboratoire de Biologie de la Reproduction, CHU de Saint-Etienne

\section{INTRODUCTION}

Le gène $D A Z$ (Deleted in AZoospermia), situé dans la région $A Z F c$ du chromosome $Y$, en position $Y q 11-23$, possède quatre copies identiques à plus de $99 \%$, associées deux par deux, de façon symétrique et inversée. Une délétion des 4 copies conduit à une azoospermie ou une oligozoospermie sévère. Des délétions partielles des copies de $D A Z$ ont été observées chez des hommes infertiles, mais aussi chez des hommes fertiles. L'absence du groupe 1 (DAZ1/DAZ2) semble associée à un phénotype plus sévère que l'absence du groupe 2 (DAZ3/DAZ4) seul, évoquant des fonctions différentes de chaque gène $D A Z$ et la possibilité d'un effet de dose.

\section{MATERIELS ET METHODES}

Patients : 200 patients infertiles et non microdélétés, et 82 témoins normospermiques et/ou fertiles seront analysés. PCR : Un des marqueurs utilisés est spécifique de la copie DAZ3. Les autres marqueurs délimitent de séquences possédant un site polymorphique permettant de distinguer les autres copies.

Migration sur DHPLC : La présence des copies DAZ1, DAZ2 et DAZ4 est analysée par DHPLC.

\section{RESULTATS}

Nos résultats préliminaires portent sur la recherche des trois premières copies pour 190 patients infertiles et 64 patients normozoospermiques.

\section{CONCLUSION}

La DHPLC permettrait une étude simple et rapide du nombre de copies de DAZ. La corrélation génotype - phénotype devrait permettre d'évaluer l'implication de chaque copie dans la spermatogenèse. Ces résultats préliminaires seront validés par la technique des SNVs (single nucleotide variants). 


\title{
Evènements de filiation et infertilité masculine
}

\author{
M. JAOUL1, D. MOLINA GOMES2, M. ALBERT2, N. LEDEE-BATAILLE3, M. BAILLY33, J. SELVA2
}

1 Psychologue, Centre Clinique de Psychothérapie, Psychiatrie Secteur 4 ; 2 Service d'Histologie, Embryologie, Cytogénétique, Biologie de la Reproduction et Génétique Médicale ; 3 Service de Gynécologie Obstétrique, Centre Hospitalier Intercommunal de Poissy-St Germain en Laye, Poissy

\section{BUT DE LA RECHERCHE}

II s'agit d'étudier l'histoire familiale (sur trois générations) d'une population d'hommes infertiles, à partir d'une grille d'évènements de filiation.

\section{METHODOLOGIE}

Ce travail a consisté à appliquer, à partir de la constitution de l'arbre généalogique réalisé lors de la consultation de génétique préalable à l'inclusion dans un protocole d'ICSI, une grille de filiation inspirée des travaux de $\mathrm{J}$. Guyotat sur les pathologies de la procréation (troubles du comportement, troubles psychosomatiques, psychose puerpérale, délires de filiation ...). Cette grille, composée de 12 items concernant la filiation instituee (la filiation dans son aspect juridique et culturel) et de 13 items concernant la filiation imaginaire (qui procède de l'imaginaire individuel et du groupe et fonctionne comme un système parthénogénétique), a été proposée à une population de 16 hommes infertiles, suivis dans le service d'AMP et à une population témoin de 18 hommes fertiles, rencontrés à la maternité dans les jours suivant la naissance de leur enfant.

Les réponses aux items dans les deux groupes ont été comparées en appliquant le test de Mann Whitney (les résultats sont considérés comme significatifs avec $p<$ $0,05)$.

\section{RESULTATS}

En ce qui concerne les items portant sur l'axe de filiation instituée, on a observé une fréquence plus grande des items "7- enfants élevés hors famille" et "9- rupture durable du lien" chez les patients infertiles. La différence entre les deux groupes est significative lorsqu'on compare le cumul de l'ensemble des items de cet axe $(p=0,019)$.
L'analyse des items concernant l'axe de filiation narcissique a montré une fréquence plus élevée pour l'item "1coïncidence naissance-décès" $(p=0,14)$ et une différence significative pour les items "5- répétition d'atteintes pathologiques/d'évènements dramatiques" $(p=0.003)$ et "8- événement de puerpéralité" $(p=0,019)$.

Les items cumulés de cet axe donnent un résultat très significativement différent $(p=0,0004)$.

\section{CONCLUSIONS}

Les résultats montrant une différence entre les deux populations au regard de certains évènements de filiation, on peut faire l'hypothèse que ceux-ci jouent un rôle dans la survenue de certaines infertilités masculines, en tant que difficulté à s'inscrire dans le défilé des générations. Les évènements mettant en cause la filiation symbolique concernent principalement le lien entre le père et le grandpère ; il s'agirait d'évoquer l'hypothèse d'un problème de rupture de la transmission comme facteur d'infertilité. Comme dans les études sur des pathologies accompagnant la procréation, on retrouve une inflation significative de la filiation narcissique, inflation qui peut porter atteinte au repérage symbolique du sujet et être à l'origine de troubles psychiques ou somatiques. Ce thème fera l'objet d'une étude ultérieure plus approfondie. 


\title{
Infertilité masculine : épidémiologie dans le sud tunisien
}

\author{
A. BAHLOUL, A. MALLEK, Y. MHADHEB, A. SAHNOUN, H. KETATA, M.N. MHIRI \\ Service Urologie, CHU H Bourguiba, Sfax, Tunisie
}

\section{INTRODUCTION}

Le but de ce travail est d'étudier l'épidémiologie de l'infertilité masculine au sud tunisien.

\section{MATERIEL ET METHODES}

II s'agit d'une étude de type cas témoins entre janvier 2001 et janvier 2003. L'âge moyen était de 34 ans avec extrême allant de 18 à 52 ans, l'infertilité est primaire dans $87 \%$ des cas et sa durée varie de 2 à 13 ans avec une moyenne de 3 ans.

\section{RESULTATS}

Nous avons retenu les facteurs de risque suivants : les antécédents familiaux d'infertilité $(O R=5,7)$, une chirurgie de la région inguinale dans la prime enfance (OR=4,83), une infection urogénitale $(O R=4)$ et le bas niveau socioéconomique $(O R=3)$. Les facteurs de risque environnementaux sont représentés par l'exposition à la chaleur $(O R=4,8)$, aux métaux lourds $(O R=2)$, aux matières plastiques et aux solvants $(O R=2,6)$ et enfin aux pesticides $(\mathrm{OR}=2)$. L'éthylisme et le tabagisme pourraient avoir un effet nocif avec un OR faible qui est respectivement de 1,8 et 1,5 .

L'analyse spermiologique a montré que l'oligospermie est fréquente $(5,4 \%)$, elle est isolée $(16 \%)$ ou associée à une asthéno-et/ teratospermie (38\%) ; L'azoospermie est notée dans $22 \%$ des cas.

Le dosage de la FSH est insuffisant pour prédire la présence de spermatozoïdes avec un taux négatif de $18,8 \%$. Le caryotype constitutionnel a révélé 8 anomalies chromosomiques. Le syndrome de Klinefelter a représenté la cause majoritaire ( 7 cas) avec un statut cytogénétique homogène $47, X X Y$ dans 6 cas et en mosaïque dans un seul cas, le syndrome de homme $X X$ a été noté dans un seul cas. L'analyse moléculaire du chromosome $Y$ a mis en évidence une micro délétion du gène DAZ. Du chromosome $Y 18 \%$ des patientsazoospermes. Dans le cadre d'imagerie médicale, nous préconisons la pratique systématique de l'écho doppler scrotal devant toute infertilité masculine. L'échographie endorectale a été pratiquée systématiquement en cas d'azoospermie excrétoire ( 5 cas de notre série).

L'imagerie par résonance magnétique explore mieux le confluent vésico-déférentiel le veru-montanum (2 cas).

\section{CONCLUSION}

Au terme de cette étude, l'infertilité masculine dans notre série serait en rapport avec une varicocèle $(34 \%)$, une infection génitale $(8 \%)$, à une anomalie cytogénétique $(12 \%)$, à une azoospermie excrétoire $(5 \%)$, une cryptorchidie $(2 \%)$ et un dysfonctionnement sexuel $(3 \%)$. Par ailleurs, elle était jugée comme idiopathique dans $36 \%$ des cas. On estime une amélioration de ce chiffre dans des études ultérieures. 


\title{
Induction de l'externalisation des résidus de phosphatidylsérine dans le spermatozoïde humain par le ionophore A23187
}

\author{
G. MARTIN, O. SABIDO, P. DURAND, R. LEVY \\ Laboratoire de Biologie de la Reproduction. CHU de Saint-Étienne
}

\section{INTRODUCTION}

La réussite d'une fécondation est dépendante de la capacité du spermatozoïde à maintenir l'intégrité de sa membrane plasmique et à effectuer les processus de capacitation et de réaction acrosomique. Une translocation de la phosphatidylserine (PS) du feuillet interne vers le feuillet externe de la membrane plasmique, un des signes précoce de l'apoptose dans la cellule somatique, a été décrite dans le spermatozoïde éjaculé. Le but de ce travail est d'analyser le lien possible entre l'externalisation des PS et les modifications membranaires relatives à la réaction acrosomique.

\section{MATERIELS ET METHODES}

Nous avons étudié en cytométrie en flux (BD Biosciences) l'effet du calcium ionophore A23187, un inducteur de la réaction acrosomique, sur l'externalisation des PS (marquage Annexine V-FITC/IP), la perméabilité membranaire (marquage Yo-Pro-1/IP), le "scrambling" membranaire (marquage merocyanine 540 ) et la réaction acrosomique complète (marquage anticorps anti-CD46-PE) chez des spermatozoïdes humains capacités provenant de sujets normospermiques.

\section{RESULTATS}

Nous avons observé que l'A23187 induit une augmentation significative de la proportion de spermatozoïdes présentant une externalisation des PS, un "scrambling" membranaire et un acrosome réagi, sans augmentation de la proportion de spermatozoïdes avec une perméabilité membranaire élevée. Par ailleurs, les spermatozoïdes présentant un externalisation des PS présentent également un "scrambling" membranaire et les spermatozoïdes réagis présentent tous un externalisation des PS.

\section{DISCUSSION}

Ces résultats suggèrent que l'externalisation des PS induite par l'A23187 est très fortement liée à la réaction acrosomique. La poursuite de l'étude de ce modèle nous permettra de déterminer s'il existe une relation entre les étapes précoces de l'apoptose et la réaction acrosomique et de préciser le rôle de cette externalisation au cours de la fécondation. 


\title{
Cinétique et caractérisation du phénomène "apoptosis-like" induit au cours de la congélation des spermatozoïdes bovins
}

\author{
G. MARTIN, O. SABIDO, P. DURAND, R. LEVY \\ Laboratoire de Biologie de la Reproduction. $\mathrm{CHU}$ de Saint-Étienne
}

\section{INTRODUCTION}

La congélation des spermatozoïdes éjaculés bovins induit une mortalité cellulaire élevée. Au cours d'une étude préliminaire, nous avons observé qu'elle s'accompagne d'un processus que nous avons qualifié d'"apoptosis-like" où apparaissent plusieurs caractéristiques précoces de l'apoptose :

- diminution du potentiel de membrane mitochondrial,

- activation des caspases,

- augmentation de la perméabilité membranaire sans apparition des caractéristiques tardives,

- pas de modification nucléaire

\section{MATERIELS ET METHODES}

Nous avons étudié en cytométrie en flux (BD Biosciences) l'effet des différentes étapes de la congélation (dilution dans le milieu de congélation, équilibration et congélation dans l'azote liquide/décongélation) des spermatozoïdes bovins sur le potentiel de membrane mitochondrial (marquage DiOC6(3)/IP), l'activité des caspases (marquage FITC-VAD-FMK/IP), la perméabilité membranaire (marquage Yo-Pro-1/IP) et la réaction acrosomique (marquage PNA-FITC/IP) ainsi que la présence d'AIF (Apoptosis Inducing Factor) en western blot.

\section{RESULTATS}

Nous avons observé que la dilution dans le milieu de congélation induisait immédiatement une diminution très importante du potentiel de membrane mitochondrial. Puis, l'équilibration s'accompagne d'un début d'activation des caspases. Après le processus complet de congélation/ décongélation, l'activité caspase est maximale et la per- méabilité membranaire apparait. Ces résultats montrent que le processus "apoptosis-like" est déclenché dès les premières étapes de la congélation. La présence d'AIF suggère la possible implication d'une voie indépendante des caspases annexe à la voie des caspases. Par ailleurs, nous avons confirmé à l'aide du marquage PNAFITC/IP que la congélation des spermatozoïdes bovins induisait la réaction acrosomique.

\section{DISCUSSION}

La poursuite de l'étude de ce modèle nous permettra d'établir de manière plus précise le lien qu'il existe entre ce phénomène apoptotique incomplet et la capacité à féconder. La détection et le contrôle de l'apoptose dans le spermatozoïde éjaculé pourraient ainsi jouer un rôle prépondérant dans le diagnostic d'infertilité et dans l'amélioration de la résistance à la congélation. 


\title{
Variations saisonnières et inter-individuelles pour différents paramètres du sperme bovin en France
}

\author{
G. MARTIN, O. SABIDO, P. DURAND, R. LEVY \\ Laboratoire de Biologie de la Reproduction. $\mathrm{CHU}$ de Saint-Étienne
}

\section{INTRODUCTION}

Peu de données concernant l'effet des saisons sur la qualité de la semence bovine sont disponibles pour la France. L'objectif de cette étude est de déterminer quels sont les paramètres spermatiques sensibles aux variations saisonnières et d'identifier des paramètres pertinents de qualification de la semence bovine.

\section{MATERIELS ET METHODES}

116 éjaculats ont été prélevés sur trois taureaux élevés en France. Les éjaculats ont été collectés puis congelés dans l'azote liquide. Le volume de semence, la concentration en spermatozoïdes, les viabilités avant et après congélation déterminées par la cytométrie en flux (SYBR14/IP) ont été évalués jusqu'à 4 fois par mois sur une période de 1 an. De plus, pour préciser l'état du noyau, le test TUNEL a été réalisé sur 24 de ces éjaculats.

\section{RESULTATS}

En automne, la concentration, les viabilités pré- et postcongélation étaient minimales. En revanche, aucune variation saisonnière significative pour le volume ni pour la résistance à la congélation n'a été observée.

Des variations inter-individuelles ont été observées pour tous les paramètres spermatiques étudiés à l'exception de la condensation nucléaire. Par ailleurs, la fragmentation de I'ADN était négativement corrélée à la viabilité. Le volume et la concentration étaient respectivement négativement et positivement corrélés à la viabilité avant congélation, à la viabilité après congélation ainsi qu'à la résistance à la congélation.

\section{DISCUSSION}

Un volume élevẽ et une faible concentration en spermatozoîdes constituent un mauvais pronostique pour la viabilité des spermatozoïdes et leur résistance à la congélation.

Les variations saisonnières ainsi que des différences inter-individuelles chez les taureaux français, donnent des informations précieuses dans le but d'optimiser les stratégies de collecte. Cette étude confirme le fait que l'analyse de la viabilité en cytométrie en flux constitue un puissant outil pour une étude objective de la qualité de la semence. 


\title{
Quantification des prostasomes par cytométrie en flux. Relation avec les paramètres spermatiques
}

\author{
B. SION1, L. JANNY1, M.P. VASSON2, G. GRIZARD1 \\ 1 Laboratoire de Biologie de la reproduction EA 975 Faculté de Médecine, Clermont Ferrand ; 2 Laboratoire de \\ Biochimie, Biologie moléculaire et nutrition EA2416. Faculté de Pharmacie Clermont Ferrand
}

\section{INTRODUCTION}

Les prostasomes sont des organelles extracellulaires ayant une structure vésiculaire produits par les cellules épithéliales de la prostate et retrouvés dans le liquide séminal. Ces vésicules ont un diamètre moyen de $150 \mathrm{~nm}$ (40-500 nm) ; elles sont entourées d'une membrane multilamellaire et contiennent de nombreuses protéines en particulier des enzymes telles que des estérases (Fabiani and Ronquist, 1995). Généralement les prostasomes sont isolés à partir des liquides séminaux puis leur quantification se fait en terme de lipides ou de protéines.

Le but de notre étude a été de réaliser dans le liquide séminal, une numération de ces vésicules par cytométrie en flux en utilisant un fluorochrome.

\section{MATERIEL ET METHODES}

L'étude a porté sur les spermes de 32 patients consultant dans le laboratoire de biologie de la reproduction pour un bilan d'infertilité. Les paramètres spermiologiques sont déterminés selon des critères de l'OMS. La quantification des prostasomes est réalisée sur le liquide séminal obtenu après centrifugation du sperme $(600 \mathrm{~g}-5 \mathrm{~min}$ puis $9000 \mathrm{~g}-20 \mathrm{~min}$ ) et en utilisant de la 6 carboxyfluorescéine $(4 \mu \mathrm{M})$ (Sigma). La numération absolue des prostasomes est réalisée après adjonction d'une quantité connue de billes utilisée comme standard interne (Flow-count fluorospheres, Beckman Coulter).

\section{RESULTATS}

Les caractéristiques des spermes étudiés sont les suivants.

\begin{tabular}{lcc}
\hline & Moyenne \pm ESM & Extrêmes \\
\hline Volume (ml) & $4,4 \pm 0,3$ & $2,0-7,5$ \\
Nombre $10^{6} / \mathrm{ml}$ & $59 \pm 8$ & $0,3-166$ \\
Mobilité progressive (\%) & $34 \pm 2$ & $4-57$ \\
Mobilité totale (\%) & $52 \pm 2$ & $17-69$ \\
Cellules rondes $10^{6} / \mathrm{ml}$ & $2,0 \pm 0,3$ & $0,5-8,0$ \\
\hline
\end{tabular}

Le nombre de prostasomes est déterminé avec un coefficient intra essai de $10 \%$.

La concentration et le nombre total de prostasomes dans l'éjaculat ont été déterminés.

\begin{tabular}{lcc}
\hline & Moyenne \pm ESM & Extrêmes \\
Nombre $\left(10^{\%} / \mathrm{ml}\right)$ & $1,08 \pm 0,06$ & $0,4-2,1$ \\
Nombre par éjaculat $\left(10^{\circ}\right)$ & $4,63 \pm 0,22$ & $2,3-8,0$ \\
\hline
\end{tabular}

La concentration en prostasomes est corrélée négativement $(p<0,018)$ avec le volume de l'éjaculat. Aucune corrélation significative n'est retrouvée avec les autres paramètres spermiologiques (nombre, vitalité, mobilités et cellules rondes).

\section{CONCLUSION}

Cette technique permet de réaliser rapidement et de façon reproductible une numération des prostasomes contenus dans le liquide séminal. D'après nos résultats préliminaires, seul le volume est corrélé négativement avec la concentration en prostasomes, suggérant que la sécrétion de prostasomes est constante et que leur quantité est sans rapport avec la qualité des spermatozoïdes.

\section{REFERENCE}

1. FABIANI R., RONQUIST G., Prostate, 1995, $27: 95-101$. 


\title{
Globozoospermie : à propos de trois cas
}

\author{
V. DROUINEAUD1, P. SAGOT2, F. MENETRIER3, N. BEHECHTI1, P. POISOT1, A. ROUGET2, \\ C. JIMENEZ 1
}

1 Service de Biologie de la Reproduction, Maternité du Bocage, Dijon ; 2 Service de Gynécologie-Obstétrique, Maternité du Bocage, Dijon ; 3 Laboratoire d'Histologie, UFR 100, Faculté de Médecine, Dijon

La globozoospermie, anomalie spermatique rare, est caractérisée par des spermatozoïdes à tête ronde sans acrosome et donc incapables de féconder naturellement un ovocyte.

La FIV-ICSI est actueliement la seule technique permettant d'obtenir des embryons à partir de spermatozoïdes provenant de sujets globozoospermiques. Toutefois les taux de fécondation demeurent faibles. Un défaut d'activation de l'ovocyte pouvant expliquer certains échecs de fécondation, une technique d'activation ovocytaire assistée peut être réalisée en association avec la FIV-ICSI.

Trois cas cliniques sont ici présentés, concernant des couples dont l'homme présente une globozoospermie. Dans les 3 cas, la technique de FIV-ICSI a été utilisée mais sans recours à une technique d'activation ovocytaire assistée. Des taux de fécondation satisfaisants, l'obtention d'embryons et la naissance d'enfants normaux ont été observées chez 2 des 3 couples.

\section{CONCLUSION}

La technique d'activation ovocytaire assistée n'est pas absolument indispensable dans le cas d'une globozoospermie, la technique classique de FIV-ICSI pouvant être utilisée seule avec succès permettant d'obtenir des taux de fécondation satisfaisants et la formation d'embryons.

A notre connaissance, il s'agit des 5ème et Gème naissances consécutives à une FIV-ICSI sans activation ovocytaire assistée dans le cadre d'une globozoospermie. 


\title{
Caractéristiques spermiologiques des hommes infectés par le virus de l'immunodéficience humaine VIH
}

\author{
L. BUJAN1, S. MARTINET1, C. PASQUIER2, M. SERGERIE1, P. MASSIP3, M. DAUDIN1 \\ 1 Groupe de recherche en fertilité humaine (EA3694) et CECOS Midi-pyrénées ; 2 Service de Virologie ; 3 Service \\ des Maladies Infectieuses et Tropicales, $\mathrm{CHU}$ de Toulouse
}

\section{INTRODUCTION}

Depuis la mise en évidence du VIH dans le sperme il y a une vingtaine d'années, le pronostic de l'infection par le VIH s'est considérablement amélioré. Dans ce contexte les couples sérodifférents ont recours à l'AMP pour concevoir sans risque de contamination de la partenaire noninfectée. La qualité du sperme de ces patients va orienter les techniques de préparation de sperme. Ainsi l'objectif de ce travail est l'étude des paramètres spermiologiques de l'homme infecté par le VIH.

\section{PATIENTS ET METHODES}

190 patients infectés par le VIH. Le groupe témoin est constitué de 218 hommes non infectés ayant prouvé leur fertilité. Après recommandation de 3 à 5 jours d'abstinence, le prélèvement de sperme est effectué au laboratoire. Pour les patients VIH, l'ARN viral est quantifié dans le plasma séminal. De plus le génome viral (ARN et ADN) est recherché dans les fractions cellulaires avant et après préparation suivant notre méthode antérieurement publiée. La charge virale plasmatique et le nombre de CD4 sont mesurées.

\section{RESULTATS}

Les antécédents andrologiques sont plus fréquemment retrouvés chez les patients $\mathrm{VIH}$ comparés au groupe témoin $(33,2 \%$ vs $20,1 \%, p<0,05)$ avec notamment un pourcentage d'infections génitales supérieur $(16,2 \%$ vs $7,6 \%$ ). $24,8 \%$ des patients VIH présentalent une anomalie à l'examen clinique versus $19,5 \%$ dans le groupe témoin $(p>0,05)$. Les patients VIH ont un index de masse corporelle inférieur aux témoins. Les volumes testiculaires droit et gauche, le délai d'abstinence ne sont pas différents des témoins. A l'inverse, le volume de l'éjaculât, la mobilité a, $a+b$, le log de la numération totale de spermatozoïdes mobiles (ntsm), la concentration en polynucléaires sont abaissés chez les patients VIH comparés au groupe témoin alors que le $\mathrm{pH}$, la mobilité $\mathrm{c}$, d et I'IAM sont aug- mentés. Toutes ces différences persistent après ajustement sur l'âge et le délai d'abstinence sauf pour le log de ntsm. Par ailleurs, après exclusion des ATCD andrologiques ou des anomalies de l'examen clinique des différences persistent pour le volume, le $\mathrm{pH}$ et la mobilité. Pour les patients VIH nous n'avons pas trouvé de différence pour les paramètres spermatiques en fonction du mode de contamination, du statut de co-infection par un virus de l'hépatite, du taux de CD4 plasmatique ou de la présence d'un traitement antirétroviral. Une charge virale positive dans le plasma séminal ne modifie pas les paramètres spermatiques alors que la concentration et la numération de spermatozoïdes sont abaissées si un génome viral est détecté dans les fractions cellulaires, le nombre de polynuclèaires étant augmentés.

\section{DISCUSSION}

Notre étude met en évidence des altérations des paramètres spermatiques chez les patients infectés par le VIH. Les résultats de la littérature sont contradictoires bien que les 3 études les plus récentes vont dans le même sens que le présent travail. Cependant dans certaines études les facteurs de confusion tels que le délai d'abstinence, l'âge du patient, les résultats de l'examen clinique n'étaient pas pris en compte. De plus la définition du groupe témoin n'est pas toujours précisé ou peut constituer un biais (ex : hommes inclus dans un programme de FIV). Les facteurs pouvant expliquer l'atteinte retrouvée restent à définir car nous n'avons pas vraiment mis en évidence de liens entre les paramètres liés à la maladie VIH ou à son traitement et les modifications spermiologiques ceci en raison du caractère transversal de cette étude et du nombre important de patients traités avec des multithérapies. II semble souhaitable de développer des études longitudinales afin d'étudier l'influence des traitements sur le sperme.

Etude ayant reçu le soutien de l'Agence Nationale de Recherche sur le SIDA (ANRSO96). 


\title{
Facteurs associés à l'excrétion du VIH-1 dans le sperme
}

\author{
L. BUJAN1, M. DAUDIN1, T. MATSUDA1, L. RIGHI2, L. BERGES2, J. IZOPET2, A. BERREB|4, \\ P. MASSIP3, C. PASQUIER2
}

1 Groupe de recherche en fertilité humaine (EA3694) et CECOS Midi-pyrénées ; 2 Service de Virologie ; 3 Service des Maladies Infectieuses et Tropicales ; 4 Unité Mère- $\mathrm{VIH}, \mathrm{CHU}$ de Toulouse

\section{INTRODUCTION}

Bien que la mise en évidence du $\mathrm{VIH}-1$ dans le sperme date de vingt ans, les facteurs associés à la présence du $\mathrm{VIH}-1$ dans les différentes fractions du sperme et à l'intermittence de son excrétion ne sont pas totalement définis. L'objet de ce travail est de tenter de préciser les facteurs de risque associés à cette excrétion.

\section{PATIENTS ET METHODES}

94 hommes infectés par le VIH-1 ont effectué 281 prélèvements de sperme et de sang. Le sperme a été soumis à deux méthodes successives de préparation antérieurement décrites. L'ARN VIH a été quantifié dans les plasma sanguins et séminaux. L'ARN et l'ADN VIH ont été recherchés dans les différentes fractions cellulaires.

\section{RESULTATS}

$14 \%$ des plasmas séminaux sont positifs en ARN et $8,7 \%$ des échantillons de sperme natif sont positifs pour l'ARN ou l'ADN VIH. 10 plasmas séminaux étaient positifs pour I'ARN alors que la charge virale plasmatique était indétectable. Le traitement antirétroviral diminue le risque d'avoir un plasma séminal positif. Le risque de retrouver du génome viral dans les cellules du sperme est quatre fois plus important en présence de polynucléaires et six fois plus si le plasma séminal est positif pour l'ARN VIH. L'excrétion du VIH dans le plasma séminal est intermittent chez $25 \%$ des patients. Cette intermittence de l'excrétion est associée à une charge virale plasmatique plus élevée et à une détection de génome viral plus fréquente dans les cellules du sperme. II est important de noter que 6 à $10 \%$ des échantillons de cellules auront un génome détecté alors que les patients présentent toujours une charge virale séminale négative. Enfin aucune fraction de spermatozoïdes obtenue après les deux méthodes successives de préparation de sperme n'a été positive pour l'ARN et l'ADN du VIH.

\section{DISCUSSION}

La présence de polynucléaires dans le sperme est un facteur de risque pour l'excrétion du VIH dans le plasma séminal. La charge virale plasmatique apparaît comme le seul facteur associé à l'intermittence de l'excrétion du VIH dans le sperme au cours du temps. Une charge virale plasmatique ou une charge virale séminale négative n'implique pas obligatoirement l'absence de virus dans le sperme. L'ensemble de ces données doit être pris en compte dans les programmes d'AMP pour couples sérodifférents et plus largement dans les campagnes de prévention de la contamination sexuelle du $\mathrm{VIH}-1$.

Etude ayant reçu le soutien de l'Agence Nationale de Recherche sur le SIDA (ANRSO96).

\section{REFERENCES}

1. CH. PASQUIER, M. DAUDIN, L. RIGHI, L. BERGES, L. THAUVIN, A. BERREBI, P. MASSIP, J. PUEL, L. BUJAN AND J. IZOPET. Sperm washing and virus nucleic acid detection to reduce HIV and hepatitis $C$ virus transmission in serodiscordant couples wishing to have children. AIDS, 14 : 2093-2099, 2000.

2. L. BUJAN, M. DAUDIN, M. ALVAREZ, P. MASSIP, J. PUEL AND C. PASQUIER. Factors associated with intermittent semen HIV-1 shedding during follow-up of an HIV-1 infected patient and efficiency of sperm processing methods despite high seminal HIV-1 RNA levels. Fertil. Steril., 78, $6: 1321-$ 1323, 2002.

3. BUJAN L., DAUDIN M., MATSUDA T., RIGHI L., THAUVIN L., BERGES L., IZOPET J., BERREBI A., MASSIP P. AND PASQUIER C. Factors of intermittent HIV-1 excretion in semen and efficiency of sperm processing in obtaining spermatozoa without HIV-1 genomes. AIDS. 18: 757-766, 2004.

4. BUJAN L., PASQUIER C., LABEYRIE E., LANUSSE P., MORUCCI M., DAUDIN M. Insemination with isolated and virologically tested spermatozoa is a safe way for human immunodeficiency type 1 virus serodiscordant couples with an infected male partner to have a child. Fertil. Steril., 82,4 :857-862, 2004. 


\title{
En ICSI, la préparation des spermatozoïdes testiculaires à l'hypotaurine améliore leur mobilité, le développement embryonnaire au stade blastocyste et le taux de grossesse
}

\author{
I. VIRAN-KLUN1, G. GRIZARD2, J. MIVSEK1, B. ZORN1, T. TOMAZEVIC1, H. MEDEN-VRTOVEC1 \\ 1 Service de gynécologie-obstétrique, CHU de Ljubljana, Slovénie ; \\ 2 Biologie du Développement et de la Reproduction-CECOS-FIV,CHU, Clermont-Ferrand,
}

\section{INTRODUCTION}

L'hypotaurine est une substance naturelle sécrétée par les cellules tubaires et les spermatozoïdes. Elle a un effet séquestrant sur les radicaux libres oxygénés et un rôle antioxydant au lieu même de la fécondation. Chez l'animal, elle améliore la capacitation des spermatozoïdes, la mobilité des spermatozoïdes épididymaires et le développement embryonnaire au stade blastocyste.

Le but de cette étude randomisée prospective (période 2002-2004) était d'évaluer le possible effet bénéfique de l'hypotaurine sur les spermatozoïdes testiculaires immobiles chez les azoospermiques inclus dans le programme de fécondation in vitro.

\section{METHODES}

69 hommes (91 cycles ICSI) avec azoospermie ont été inclus dans cette étude. Tous avaient des spermatozoïdes immobiles à la décongélation.

Dans 48 cycles ( 38 hommes) les spermatozoïdes testiculaires immobiles ont été préparés en ajoutant $50 \mathrm{mM}$ d'hypotaurine au milieu Sperm Preparation (Medi-Cult, Denmark); dans les 43 cycles restant ( 31 men) il n'y a pas eu d'ajout d'hypotaurine.

L'ICSI a été réalisée selon la méthode classique, mais sans PVP.

Tous les embryons ont été cultivés jusqu'au stade blastocyste dans des milieux séquentiels (BlastAssisstSystem, Denmark). Les résultats cliniques entre les deux groupes (développement embryonnaire jusqu'au stade embryonnaire et taux de grossesse) ont été comparés grâce au Chi-Square test et au test de Mann-Whitney. La différence était significative pour $P<0.05$.

\section{RÉSULTATS}

Après préparation du tissu testiculaire à l'hypotaurine, 41 $(89 \%)$ cycles ICSI ont été réalisés avec des spermatozoïdes mobiles.

En général, la préparation à l'hypotaurine améliorait le développement embryonnaire au stade blastocyste $(41 \%$ vs $10 \% ; P<0,05)$ et le taux de grossesse $(23 \%$ vs $7 \%$; $\mathrm{P}<0,05)$.

Chez les spermatozoïdes qui étaient immobiles après la préparation à l'hypotaurine (6 cycles), le développement embryonnaire était meilleur et le taux de grossesse supérieur $(32 \%$ vs $7 \% ; P<0,05)$ à ceux obtenus avec les spermatozoïdes testiculaires immobiles non traités par l'hypotaurine.

\section{CONCLUSION}

L'hypotaurine améliore la mobilité des spermatozoïdes testiculaires et les résultats cliniques de I'ICSI. Elle agit non seulement sur la mobilité des spermatozoïdes (sélection des spermatozoïdes vitaux) mais probablement aussi sur les autres paramètres de la qualité du sperme (comme l'intégrité de l'ADN), ce qui améliore d'autant les résultats cliniques obtenus avec les spermatozoïdes testiculaires. 


\title{
Taux cumulatif de grossesses après ICSI utilisant uniquement des spermatozoïdes testiculaires conge- lés chez 51 hommes présentant une azoospermie non obstructive
}

\author{
C. GIORGETTI, E. HANS, J. SALZMAN, P. TERRIOU, V. URRUTIA, J.M. CHINCHOLE, \\ J.P. FRANQUEBALME, E. GLOWACZOVER, B. BARRI, V. CHABERT-ORSINI, M.C. SITRI, G. RUF, \\ R. ROULIER
}

Institut de Médecine de la Reproduction, Marseille

\section{INTRODUCTION}

Plusieurs travaux ont montré que dans les azoospermies non obstructives (ANO) les résultats de l'ICSI étaient similaires lors de l'utilisation de spermatozoïdes frais ou congelés après prélèvement chirurgical testiculaire (TESE). Dès 1998 nous avons décidé de réaliser une cryoconservation lors de la biopsie diagnostique et d'effectuer une ICSI de façon différée. Le but de ce travail est d'évaluer au 30 juin 2004 l'efficacité de cette pratique pour les cryoconservations de spermatozoïdes effectuées entre 1998 et 2002 en terme de taux cumulatif de grossesses par couple à partir d'un seul prélèvement testiculaire.

\section{MATERIEL ET METHODE}

Le classement en ANO utilise plusieurs critères : volume de l'éjaculat, biochimie séminale, taille des testicules, $\mathrm{FSH}$, échographie, mais seule l'histologie du jour du TESE nous a permis de confirmer le diagnostic. Le prélèvement chirurgical est bilatéral, unique et le plus large possible (575 mg en moyenne par testicule). L'échantillon est déposé dans une boite de pétri contenant $4 \mathrm{ml}$ de milieu de culture et nous effectuons une dissection mécanique sous loupe binoculaire pendant 5 à 10 minutes à l'aide de 2 lames de verre. Le milieu de culture est récupéré et traité par un percoll monophase $(80 \%)$ centrifugé pendant $20 \mathrm{mn}$ à $600 \mathrm{~g}$. Le traitement de l'échantillon est renouvelé et les 2 phases $80 \%$ sont réunies et lavées. Le culot de centrifugation est remis en suspension dans 250 $\mu l$ de milieu. La congélation est effectuée en paillettes de $150 \mu$ l après une dilution $v / v$ avec le milieu de congélation. Le volume final par paillette est ajusté entre 50 et $100 \mu \mathrm{l}$ en fonction du nombre de spermatozoïdes isolés.

\section{RÉSULTATS}

Au total 111 TESE ont été réalisées. Nous avons pu congeler des spermatozoïdes ( 3 à 10 paillettes) chez 51 hommes dont 9 Sertoli Cell Only Syndrome, 20 arrêts de la spermatogénèse et 22 hypospermatogénèses sévères (très rares spermatozoïdes intra-luminaux). En différé 93 ICSI ont été effectuées au cours desquelles 17 congélations embryonnaires ont été possibles. Le taux de fécondation a été de $61 \%$ (413 embryons/679 ovocytes injectés). L'âge moyen des femmes est de 31,4 ans et le nombre moyen d'embryons transférés 2,2. Au total 33 grossesses ont été obtenues : 5 ASP (16\%) - 0 GEU - 5 grossesses évolutives sup. à 22 SA - 23 accouchements et 31 enfants nés tous en bonne santé.

\section{CONCLUSION ET DISCUSSION}

Le taux cumulatif de grossesses proche de $50 \%$ dès le $2^{\circ}$ cycle d'ICSI montre que cette pratique doit désormais s'imposer par rapport aux prélèvements folliculaires et testiculaires synchrones. De plus la cryoconservation, en plusieurs paillettes, de spermatozoïdes obtenus après TESE évite de répéter des gestes chirurgicaux qui ne sont pas sans inconvénients.

\begin{tabular}{lccccc}
\hline Cycle ICSI & $\mathbf{1}^{\circ}$ & $\mathbf{2}^{\circ}$ & $\mathbf{3}^{\circ}$ & $\mathbf{4}^{\circ} \mathbf{e t} \mathbf{5}^{\circ}$ & Emb. congelés \\
\hline Nb de Pct folliculaires & 51 & 26 & 10 & 6 & 15 transferts \\
Nb de Transferts & 51 & 25 & 9 & 5 & 2 grossesses \\
Grossesses & 16 & 9 & 3 & 3 & $33(65 \%)$ \\
\hline TCG */couple & $16(31 \%)$ & $25(49 \%)$ & $28(55 \%)$ & $31(61 \%)$ & $31 \%$ \\
\hline
\end{tabular}

*Taux cumulatif de grossesses pour les 50 couples 


\title{
Naissance d'enfants d'hommes infertiles azoosper- miques avec taux élevés de la FSH sérique
}

\author{
B. ZORN1, I. VIRANT-KLUN1, G. GRIZARD1, L. JANNY2, J. HERMABESSIERE1, J.L. POULY2, \\ S. DROBNIC1, H. MEDEN-VRTOVEC1
}

1 Service de gynécologie obstétrique, centre hospitalier universitaire de Ljubljana, Ljubljana, Slovénie ; 2 Biologie du développement et de la reproduction-CECOS-FIV, centre hospitalier universitaire, Clermont-Ferrand, France

\section{INTRODUCTION}

La recherche de spermatozoïdes testiculaires peut s'avérer positive même chez les hommes azoospermiques avec taux élevé de FSH. Quelques articles rapportent que la FSH élevée influe négativement sur la spermatogenèse, la qualité du sperme (anomalies chromosomiques) et le développement embryonnaire jusqu'au stade blastocyste en FIV. Le but de cette étude a été de comparer les résultats cliniques de l'ICSI précédée de la biopsie testiculaire (TESE-|CSI) en cas d'azoospermie obstructive (OA) et non obstructive (NOA) et d'évaluer le rôle de la TESE-ICSI chez les hommes avec FSH élevée.

\section{MATERIEL ET METHODES}

II s'agit d'une étude rétrospective des résultats cliniques de 320 cycles de TESE-ICSI avec spermatozoïdes testiculaires congelés, recueillis dans deux centres de FIV entre 1997 et 2003. Nous avons comparé les résultats cliniques entre les deux centres puis parmi les hommes avec $O A$ et NOA. Le type d'azoospermie avait été précédemment déterminée en fonction de l'anamnèse, du volume testiculaire, des taux de FSH et d'inhibine B, des marqueurs biochimiques (Alphaglucosidase, fructose) et du score histologique de Johnsen. Nous avons évalué le rôle de la TESE-ICSI chez les hommes avec taux élevés de FSH.

\section{RESULTATS}

Dans les 2 centres de Clermont-Ferrand (France) et de Ljubljana (Slovénie), la proportion d'azoospermiques parmi les nouveaux couples est pratiquement identique $(5,3 \%$ et $6,5 \%)$, mais le taux d'azoospermiques se soumettant à une TESE est plus élevé $(78,6 \%)$ à Ljubljana qu'à Clermont-Ferrand $(23,2 \%)$. A Ljubljana, plus de
TESE-ICSI qu'à Clermont-Ferrand sont pratiquées pour NOA $(68,5 \%$ contre $49,4 \%)$. En dépit de ces disparités, il n'y a pas de différences significatives en terme de taux de fécondation $(49,0 \%$ contre $49,0 \%)$, de taux d'embryons de bonne qualité $(67,0 \%$ contre $65,0 \%)$, de taux de grossesse $(21,0 \%$ contre $26,6 \%)$ et de taux de fausses couches $(14,2$ contre $14,3 \%)$. Pareillement, il n'y a pas de résultats différents entre OA et NOA. A Clermont-Ferrand, les TESE ne sont proposées qu'aux patients avec $\mathrm{FSH}<30$ I.U./L. A Ljubljana, 27 cycles ICSI ont été réalisés chez 11 patients avec NOA et FSH > 30 I.U./L. Cinq grossesses ont été obtenues (taux de grossesse par cycle de 19\%), trois d'entre elles ayant abouti à l'accouchement d'un enfant sain.

\section{CONCLUSION}

Devant une NOA à FSH élevée, une TESE ICSI peut être discutée avant le recours au don de sperme. 


\title{
Intérêt de la cryoconservation des ovocytes matures chez des couples pour lesquels aucun spermatozoï- de n'a été retrouvé le jour de la fécondation in vitro
}

\author{
I. VIRANT-KLUN, L. BACER-KERMAVNER, T. TOMAZEVIC, H. MEDEN-VRTOVEC \\ Department of Obstetrics and Gynaecology, University Medical Centre Ljubljana, Slovenia
}

\section{INTRODUCTION}

Bien que toutes les précautions soient prises pour disposer de spermatozoïdes le jour de la tentative de fécondation in vitro, il peut cependant arriver très rarement d'obtenir des ovocytes chez la femme et aucun spermatozoïde chez son partenaire. Dans ce cas, la cryoconservation des ovocytes peut s'avérer être un bon moyen pour réaliser, en différé, une tentative de fécondation in vitro avec les spermatozoïdes du partenaire ou d'un donneur.

\section{BUT}

Evaluer l'intérêt de la cryoconservation des ovocytes chez des couples inclus dans un programme de fécondation in vitro pour une infertilité masculine (aucun spermatozoïde le jour de la tentative de fécondation in vitro).

\section{METHODES}

Les ovocytes matures (métaphase II) sont obtenus par aspiration sous échographie et congelés/décongelés (débarrassés des cellules de la granulosa) selon la méthode de Fabri et al (2001). Actuellement, nous utilisons les milieux de congélation/décongélation fournis par Médicult (Yylinge, Danemark) et fabriqués selon Fabri et al.

\section{RESULTATS}

Entre 2002 - 2003, nous avons congelé les ovocytes de deux couples pour lesquels aucun spermatozoïde n'a été retrouvé chez le partenaire. Le premier couple (âge de la femme : 32 ans) vient de l'étranger et nous dit que lors du spermogramme, des spermatozoïdes ont été retrouvés mais le jour de la fécondation in vitro, aucun spermatozoïde n'est retrouvé dans l'éjaculat. Une biopsie testiculaire a été réalisée avant la fécondation in vitro, un spermatozoïde a été vu avant la congélation mais le jour de la fécondation in vitro aucun spermatozoïde n'a été retrouvé après décongélation du tissu testiculaire. Pour les deux couples, les ovocytes ont été congelés, le jour de la ponction : 5 ovocytes et 12 ovocytes respectivement pour le $1 \mathrm{er}$ et 2ème couple. Chez les deux hommes une nouvelle recherche y compris sur une biopsie testiculaire n'a pas permis de retrouver des spermatozoïdes. Les deux couples ont décidé une fécondation de leurs ovocytes cryoconservés avec des spermes de donneur. Pour le 1er couple une ICSI a été réalisée et sur les 2 ovocytes qui ont "survécu" à la congélation/décongélation ( 2 sur 5 ) aucune fécondation n'a été obtenue. Pour le 2ème couple, une ICSI a été réalisée sur 9 ovocytes qui ont survécu à la congélation/décongélation (9 sur 12), 8 embryons ont été obtenus et 6 se sont développés jusqu'au stade blastocystes. 2 blastocystes ont été transférés et 4 ont été congelés. Une grossesse est survenue et un garçon est né à terme, en bonne santé. Le couple envisage une 2ème grossesse avec les blastocystes congelés.

\section{CONCLUSION}

La cryoconservation des ovocytes présente un réel intérêt chez les couples pour lesquels aucun spermatozoïde n'est retrouvé le jour de la fécondation in vitro. II est ainsi possible d'obtenir une grossesse en réalisant en différé une fécond ation in vitro des ovocytes avec les spermatozoïdes du partenaire ou le sperme d'un donneur.

\section{REFERENCE}

1. FABBRI R, PORCU E, MARSELLA T, ROCCHETTA G, VENTUROLI S, FLAMIGNI C. Human oocyte cryoconservation: new perspectives regarding oocytes survival. Hum. Reprod., 2001, 16(3) : 411-416. 


\title{
ICSI risques potentiels de la technique et problèmes éthiques soulevés par la technique
}

\author{
P. SOARES, L. GUY, L. SAVAREUX, N. VEDRINE, J.P. BOITEUX \\ Service d'Urologie, CHU Clermont-Ferrand
}

L'ICSI a révolutionné le traitement de la stérilité masculine. Cette technique développée depuis 1992 chez l'homme permet, par sa méthode, de contourner les différents obstacles de la sélection naturelle à la fécondation. Cette sélection, aussi stricte que complexe, aboutit à la rencontre d'un spermatozoïde, aussi parfait que possible, et d'un ovocyte.

Avec I'ICSI, un grand pas est franchi. Mais cette technique artificielle de procréation présente des risques et soulève des problèmes éthiques.

Le taux global d'ovocytes fécondés selon le rapport de Eshre en 1998 est de l'ordre de 58,7\% avec un taux de grossesses évolutives de $38,3 \%$ et un taux d'accouchement de $32,9 \%$.

Seul le suivi sur plusieurs années des enfants nés par la technique ICSI permettra de déterminer tous les risques de cette technique. Se pose la question du devenir de ces enfants.

Les risques craints sont nombreux. Ils peuvent être liés aux manipulations qui peuvent altérer les ovocytes ou les spermatozoïdes. L'introduction de mitochondries spermatiques dans l'ovocyte, habituellement absentes dans le processus naturel de fécondation, pose le problème de leur devenir. Les conséquences d'injections de substances telles que le PVP ou l'utilisation d'enzymes inexistantes dans le milieu naturel sont inconnues. A défaut d'une sélection naturelle, le biologiste utilise l'ovocyte et le spermatozoïde fécondant par simple sélection sur des critères morphologiques prenant ainsi le risque d'utiliser des gamètes anormaux. La transmission d'une anomalie chromosomique parentale méconnue ou de novo aboutit à des malformations ou à la transmission de l'infertilité. Il existe une différence significative des taux d'anomalies malformatives et chromosomiques entre la technique ICSI et la population générale Centre Est avec un rapport de $1,54(p<0,005)$. En utilisant des spermatozoïdes épididymaires, il n'y a pas de différence significative $(p=0,6)$ entre la technique ICSI et la population générale (Registre Centre Est) ; En revanche l'utilisation de spermatozoïdes testiculaires augmente le taux de malformations et d'anomalies chromosomiques avec un rapport de $3,14(p<0,005)$ par rapport à la population générale (Registre Centre Est);

Cette technique sans expérimentation animale complète ne peut être évaluée qu'après la naissance et le suivi à long terme des enfants. Quelle marge d'erreur est alors acceptée pour cette technique?

Quelle pression exercent les parents, les associations sur les médecins pour réaliser l'ICSI malgré le manque de recul médical sur cette technique?

L'ICSI est une importante avancée dans le domaine de la procréation médicale assistée (PMA). Cette technique aussi innovante que spectaculaire contourne les barrières naturelles à la fécondation et permet aux hommes stériles d'avoir des enfants. Se pose alors le problème éthique de l'ICSI et la manipulation des gamètes qu'elle entraîne. 


\title{
Délai moyen pour concevoir en assistance médicale à la procréation avec don de spermatozoïdes
}

\author{
C. METZLER-GUILLEMAIN1, F. HOLLECKER1, J. SAIAS-MAGNAN1, O. PAULMYER-LACROIX1, \\ G. PORCU2, B. ROSSIN3, R. BOSCHET4, J.M. GRILLO1
}

1 CECOS Marseille-CHU, Laboratoire de Biologie de la Reproduction, Hôpital La Conception, Marseille ; 2 Centre de Procréation Médicalement Assistée, Hôpital La Conception, Marseille ; 3 Fondation St Joseph, Marseille ; 4 Clinique St Michel, Toulon

La majorité des couples candidats à L'Assistance Médicale à la Procréation avec don de spermatozoïdes (AMP-D) sont des couples dont le conjoint est atteint d'azoospermie sécrétoire, pour qui une tentative d'ICSI avec biopsie testiculaire n'a pu aboutir. Avant d'être candidats à l'AMP$D$, ces couples ont donc eu un parcours long et difficile au cours duquel la biopsie testiculaire a représenté l'ultime espoir, celui-ci ayant finalement laissé place à un diagnostic de stérilité masculine définitive. Le recours à l'AMP-D apparaît alors comme la seule possibilité de vivre une grossesse. A partir du moment où les couples sont volontaires pour l'AMP-D, nombreux sont ceux qui se demandent combien de temps il leur faudra encore attendre avant de concevoir. Nous avons donc effectué une étude rétrospective sur 2 ans et demi, afin d'évaluer le délai moyen pour concevoir en AMP avec don de spermatozoïdes dans notre CECOS.

De janvier 2001 à juillet 2003, 93 dossiers provenant de 6 centres cliniques ont été acceptés pour une première demande d'AMP avec don de spermatozoïdes, 83 pour IAD (89\%), 10 pour FIV-D. Seuls 81 couples (87\%) ont réellement débuté des tentatives. 6 couples ont abandonné leur démarche, 2 se sont séparés.

Le délai minimum d'attente entre le moment où les dossiers sont acceptés en commission pluri-disciplinaire, et le moment où nous délivrons des paillettes de donneur est de 6 mois. En moyenne, les couples commencent les tentatives 9 mois après l'acceptation du dossier.

Sur les 81 couples qui ont effectivement débuté, 54 ont obtenu une grossesse $(67 \%)$, celle-ci survenant en moyenne 6.11 mois après le début des tentatives.

Au total, un délai moyen de 15 mois pour concevoir apparaît long pour les couples, mais est en réalité un délai relativement court, au cours duquel il est nécessaire que les couples puissent rencontrer plusieurs fois les différents acteurs de l'AMP-D afin de s'y préparer au mieux. 


\title{
Apport de l'autoconservation de sperme dans la prise en charge des oligozoospermies extrêmes
}

\author{
V. LEFEBVRE-KHALIL1, I. KOSCINSKI1, J.M. RIGOT2, A. DEFOSSEZ1 \\ 1 Laboratoire de Biologie de la Reproduction, Hôpital Jeanne de Flandre, CHRU Lille ; 2 Service d'Andrologie, \\ Hôpital Calmette, CHRU Lille
}

\section{INTRODUCTION}

Dans cette étude rétrospective, nous avons dressé le bilan de 24 mois d'activité d'autoconservation systématique de sperme chez 75 patients souffrant d'oligozoospermie extrême confinant à l'azoospermie, au sein du laboratoire d'Assistance Médicale à la Procréation du CHRU de Lille.

\section{MATERIEL ET METHODES}

Les recueils de sperme, traités par une méthode de préparation dérivée de l'"Extended Sperm Preparation" (ESP), ont permis de séparer les patients en deux groupes : le groupe "cryptoazoospermie" $(n=39)$ lorsque la numération spermatique était inférieure à 1000 spermatozoïdes par éjaculat, et le groupe "oligozoospermie extrême" ( $n=36)$ lorsqu'elle oscillait entre 1000 et 100000 spermatozoïdes par éjaculat. Le reste de la préparation a alors été cryoconservé selon un protocole standardisé. L'ensemble des patients a bénéficié d'une tentative d'ICSI et les résultats ont été comparés à ceux obtenus pour une population témoin $(n=24)$ pour laquelle la numération spermatique était supérieure à 100000 spermatozoïdes par éjaculat.

\section{RESULTATS}

Tous les patients présentant une oligozoospermie extrême $(100 \%)$ et $83,3 \%$ des cryptoazoospemes ont pu bénéficier d'une tentative d' ICSI avec le sperme frais recueilli le jour de la ponction ovocytaire. Pour $16,7 \%$ des cryptoazoospermes, il a été nécessaire de recourir à l'utilisation de sperme autoconservé ou de sperme recueilli la veille de la tentative et mis en culture pendant 24 heures. Les taux d'implantation et de grossesse clinique obtenus en cas de cryptoazoospermie (respectivement $10 \%$ et $18,5 \%$ ) sont inférieurs à ceux observés en cas d'oligozoospermie sévère $(14,2 \%$ et $22,2 \%$ ) et au sein du groupe témoin $(14,8 \%$ et $20,8 \%)$.

\section{CONCLUSION}

Cette prise en charge est certes fastidieuse mais elle permet de limiter le recours au prélèvement chirurgical, d'éviter l'annulation de certaines tentatives et permet aux couples d'appréhender plus sereinement leur parcours d'AMP. 


\title{
Analyse d'une enquête menée auprès des hommes conservant leur sperme au CECOS Alsace
}

\author{
A. CLAVERT
}

Service Biologie de la Reproduction, Cecos Alsace, Strasbourg

\section{PROBLÉMATIQUE}

Nous assistons à une augmentation du nombre de conservation à visée préventive liée à la plus grande sensibilisation de nos collègues, à l'amélioration du pronostic des maladies traitées et aux progrès des AMP. Simultanément nos patients répondent mal à nos relances annuelles, $37 \%$ demandent la prolongation de la conservation et seulement $10 \%$ demandent une destruction de leur stock de paillettes. Les spermes "orphelins" représentent 53\% des conservations.

\section{BUTS DE L'ETUDE}

L'autoconservation du sperme que nous considérons simplement comme un moyen de préserver la fertilité n'est pas un acte purement technique. L'étude du comportement des patients par rapport au devenir de leurs gamètes doit nous donner des indications sur la représentation qu'ils se font de cette réalité. En clarifiant ce que l'autoconservation représente, nous serons plus à même de permettre à ces hommes de pouvoir prendre une décision soit de réutilisation soit de destruction

\section{MATERIEL ET METHODES}

Nous avons envoyé 1478 questionnaires à tous les hommes conservant leur sperme au CECOS. Les questions portent sur:

- leur situation familiale

- l'évolution de leur fertilité

- leur décision par rapport à la poursuite de leur conservation

- des questions ouvertes portant sur leur décision, et la signification de la conservation et l'image de leur sperme congelé.

\section{RESULTATS}

Le nombre de retour du courrier augmente avec le temps, ce qui correspond à la mobilité des personnes. Les nonréponses, le courrier est arrivé à domicile mais sans réponse, sont indépendantes, de la durée de la conservation, de l'âge au moment de la conservation, de l'âge au moment du questionnaire, de l'indication (chimiothérapie ou vasectomie)

Questions qui se posent : Pourquoi le comportement des hommes est indépendant de l'histoire médicale ? Pourquoi la volonté de poursuivre la conservation est souvent indépendante du projet procréatif ? Pourquoi des "grand pères" veulent-ils poursuivre la conservation de leur sperme? 


\title{
Les hémi-scrotums droit et gauche sont-ils fonctionnellement équivalents?
}

\author{
R. MIEUSSET, B. BENGOUDIFA \\ EA 3694 Recherche en Fertilité Humaine, CHU Toulouse
}

\section{OBJECTIFS}

Dans plusieurs études, la température scrotale a été évaluée par la mesure de la température d'un seul des 2 hemi-scrotums. Notre objectif était d'évaluer l'équivalence fonctionnelle supposée des 2 hemi-scrotums en ce qui concerne leur fonction thermorégulatrice.

\section{MATERIELS ET METHODES}

8 hommes fertiles volontaires (20-48 ans).

\section{Protocole}

4 positions successives ( 15 min chacune) : allongé, debout, assis jambes écartées, assis jambes croisées, à l'état nu puis habillement usuel (température ambiante stable entre 22 et $30^{\circ} \mathrm{C}$ ). Les températures scrotales sont enregistrées toutes les 2 min par une centrale de mesure (Amritsu : AM-7001K) au moyens de sondes thermiques.

\section{Analyses des données}

Elle est réalisée à partir des données soit observées, soit transformées. Données transformées : pour chaque indivi$\mathrm{du}, 1$ ) on détermine la valeur la plus basse observée pour la température scrotale à droite et à gauche à l'état nu ; celle-ci est considérée comme référence : la valeur 1,0 lui est attribuée ; 2 ) toutes les valeurs des températures scrotales (nu puis habillé) sont ensuite exprimées en fonction de cette référence. Une valeur moyenne par mesure pour les 8 sujets est ensuite calculée à partir des données transformées.

\section{Résultats préliminaires}

1. A l'état nu, la plage de variation (valeurs entre lesquelles varie la température) de la température scrotale est plus importante à gauche (de 1,00 à 1,15 ) qu'à droite (de $1,00$ à 1,08$)$.
2. A l'état habillé, la plage de variation de la température scrotale est plus importante à droite (de 1,04 à 1,10) qu'à gauche (de 1,08 à 1,12).

3. Par rapport à l'état nu, la variation de la température scrotale à l'état habillé est en moyenne réduite de $28 \%$ à droite (extrêmes : $9 \%-49 \%$ ) et de $54 \%$ à gauche (extrêmes : $26 \%-73 \%$ ).

\section{DISCUSSION}

Soumis à un environnement identique, les deux hémiscrotums ne se comportent pas de la même façon au plan thermique, que ce soit à l'état nu ou à l'état habillé, et cela indépendamment de la position. Ces résultats préliminaires laissent entrevoir plusieurs hypothèses en cours d'exploration par l'utilisation d'autres modèles d'analyse dans d'autres conditions. Si ces résultats sont confirmés, cet comportement dissemblable des deux hémi-scrotums soulève la question d'une part du support physiologique à cette différence, d'autre part de l'intérêt fonctionnel de cette différence pour la spermatogenèse. 


\title{
L'éléphantiasis scrotal
}

\author{
A. MALLEK, Y. MHADHEB, S. KETATA, A. BOUHLEL, A. SAHNOUN, A. BAHLOUL, M.N. MHIRI
}

Service d'Urologie CHU Habib Bourguiba, Sfax, Tunisie

\section{INTRODUCTION}

L'éléphantiasis scrotal est une altération hypertrophique du derme scrotal et des tissus sous-jacents, elle traduit une altération du système de drainage lymphatico-veineux de tout le tégument recouvrant les organes génitaux externes masculins. Le but de ce travail est de dégager les particularités éthiopathogéniques, cliniques et thérapeutiques de cette affection tout en insistant sur ses répercussions psychosociales et sexuelles.

\section{OBSERVATION}

Il s'agit d'un patient âgé de 52 ans originaire de Libye sans antécédents pathologiques particuliers qui a consulté pour une augmentation progressive du volume des bourses et du pénis évoluant depuis 4 ans ce qui a rendu toute activité sexuelle impossible. A l'examen clinique les bourses sont très augmentées de taille, la verge est enfuie dans le scrotum avec une peau épaissie. L'enquête étiologique à la recherche de microfilaires s'est révélée négative. Le patient a bénéficié d'une excision des tissus malades, une scrotoplastie et une reconfection de peau pénienne à partir de celle de la muqueuse préputiale restée en quantité suffisante. L'aspect final est considéré comme esthétiquement satisfaisant.

L'évolution est bonne après un recul de 6 mois : l'aspect esthétique est acceptable mais la pratique sexuelle reste insuffisante, le patient souffrait d'une dysfonction érectile.

\section{CONCLUSION}

L'éléphantiasis scrotal est une pathologie rare ; son diagnostic est clinique; elle est peut être la cause d'un handicap fonctionnel et psychologique à l'origine d'un dysfonctionnement sexuel. Le traitement est d'abord chirurgical se basant sur l'exérèse totale des tissus atteints et le rétablissement d'une bonne esthétique ce qui rétablirait du moins en théorie la fonctionnalité de la verge. Mais d'autres facteurs responsables d'une dysérection sous jacente peuvent apparaître, celle-ci devrait être traitée de façon systématique. 


\title{
Effets de la position et de l'habillement sur la dynamique de la température scrotale
}

\author{
R. MIEUSSET, T. MATSUDA, L. BUJAN \\ EA 3694 Recherche en Fertilité Humaine, CHU Toulouse
}

\section{OBJECTIFS}

Evaluer l'effet de la posture et de I'habillement sur la dynamique des températures scrotale, cutanée, axillaire et rectale.

\section{MATERIELS ET METHODES}

8 hommes fertiles volontaires (20-48 ans).

\section{Protocole}

4 positions successives ( $15 \mathrm{~min}$ chacune) : allongé, debout, assis jambes écartées, assis jambes croisées, à l'état nu puis habillement usuel. Les températures scrotales (Ts), thoracique, axillaire et rectale sont enregistrées toutes les 2 min par une centrale de mesure (Amritsu : $\mathrm{AM}-7001 \mathrm{~K}$ ) au moyens de sondes thermiques.

\section{Analyses des données}

Pour tenir compte de la variabilité de la mesure intra-individuelle et inter-individuelle : 1) La moyenne de la première mesure réalisée chez chacun des 8 sujets lors de la première posture (allongé, nu) est considérée comme référence : la valeur 1.0 lui est attribuée; 2) Toutes les moyennes des mesures suivantes des 8 individus effectuées (toutes les $2 \mathrm{~min}$ ) nu puis habillé sont exprimées en fonction de cette référence ; 3 ) Les pentes de la courbe des valeurs obtenues pour chaque position à l'état nu ou habillé sont comparées par un test ANOVA à 2 variables indépendantes : habillement (oui/non), et temps réel en minutes.

\section{RESULTATS-DISCUSSION}

\section{Dynamique des températures selon la position}

A l'état nu, la Ts tend à diminuer Debout (position dans laquelle la Ts atteint ses valeurs les plus basses) et à augmenter Allongé, Assis jambes écartés et Assis jambes croisées (dans cette dernière position la Ts atteint ses valeurs les plus hautes).

II apparaît une spécificité du scrotum : la dynamique de la Ts est à la fois de type cutané (thorax) et de type sexué (creux axillaire) ; mais l'intensité des modifications est plus grande pour la Ts. Les différentes positions sont sans effet significatif sur la température rectale.

\section{Effets de l'habillement sur la dynamique des tempé- ratures}

La pente de la courbe des températures:

1. est significativement réduite en position Allongé et Debout : la tendance à l'augmentation (Allongé) ou à la diminution (Debout) sont de moindre intensité Habillé versus $\mathrm{Nu}$.

2. s'inverse en position Assis jambes écartés : Nu = augmentation ; Habillé = diminution.

3. la pente n'est pas différente Habilié versus Nu en position Assis jambes croisées.

Si l'habillement augmente la valeur de la température scrotale quelle que soit la position, son influence sur la dynamique de cette température est dépendante de la position. 


\title{
Hypospadias : conséquences psychosociales, urologiques, sexuelles et reproductives à l'âge adulte
}

\author{
R. MIEUSET, M. SOULIE \\ Sce Urologie-Andrologie, 1 EA 3694 Recherche en Fertilité Humaine, Toulouse
}

L'hypospadias est une anomalie du développement dont la traduction la plus évidente est une position ectopique du méat urétral situé soit sur la face ventrale du gland ou du pénis, soit en position scrotale ou périnéale. La réparation chirurgicale a pour objectifs de permettre une miction en position debout, une pleine sexualité, et d'obtenir une apparence cosmétique de la verge aussi normale que possible. Une analyse de la littérature a été réalisée.

1. Patients opérés dans l'enfance. Les complications urologiques les plus fréquentes sont les fistules, les diverticules, les sténoses urétrales, et les difficultés mictionnelles. Le risque infectieux n'est pas augmenté. Le développement psychosocial n'est pas affecté en général, la maturation et le début de l'éveil sexuels sont normaux. Cependant, ces patients présentent une plus grande difficulté à établir des contact avec le sexe opposé. A l'âge adulte, les troubles de l'érection et de l'éjaculation sont fréquents.

2. Patients opérés à l'âge adulte. Les résultats urologiques de la chirurgie sont moins bons et les complications plus fréquentes que chez l'enfant. Absence de données sur la sexualité.

3. Patients qui ne seront jamais opérés. Malgré l'absence d'étude spécifique, ces patients ne semblent pas différer de ceux opérés dans l'enfance pour ce qui est des troubles mictionnels, du développement psycho-sexuel et de la sexualité.

4. Capacités reproductives. Les hormones impliquées dans les fonctions testiculaires ne sont en général pas perturbées, que ce soit chez l'enfant ou chez l'adulte. Toutefois, il existe des facteurs cliniques, histologiques, et spermiologiques susceptibles de retentir sur la fertilité. II n'existe pas à ce jour d'évaluation de la fréquence de l'infertilité dans la population des hommes non opérés ou ayant été opérés dans l'enfance pour un hypospadias. 


\title{
Bloc en hydroxylase : une cause rare d'hypofertilité masculine et de tumeur du testicule
}

\author{
D. DELAVIERRE1, P. EMY2 \\ 1 Uro-andrologue, 2 Endocrinologue, CHR d'Orléans, France
}

\section{CAS CLINIQUE}

Un homme de 29 ans est adressé en consultation d'uroandrologie par un médecin d'un centre d'AMP pour la prise en charge d'une tumeur testiculaire bilatérale découverte sur une échographie lors d'un bilan d'hypofertilité (oligoasthénotératospermie sévère avec volume éjaculé normal). Cette échographie montre la présence de plusieurs nodules hétérogènes des 2 testicules avec des épididymes sains. Le patient a des antécédents d'hyperplasie congénitale des surrénales par bloc en 21 hydroxylase et reçoit des glucocorticoïdes. Il est asymptomatique sur le plan uro-génito-sexuel et ne présente pas de signes d'hypogonadisme. L'examen palpe plusieurs nodules indurés des 2 testicules, sans anomalie des épididymes et des déférents et sans varicocèle. Le bilan hormonal (testostérone totale, $\mathrm{LH}, \mathrm{FSH}$, prolactine et $17 \mathrm{~b}$ estradiol) est normal. La spermoculture est stérile. Le caryotype est 46 $X Y$. Les marqueurs tumoraux testiculaires sont négatifs.

\section{DIAGNOSTIC}

Ce patient présente des inclusions surrénaliennes intratesticulaires en rapport avec sa maladie endocrinienne.

A quoi correspondent ces inclusions surrénaliennes ? Les inclusions surrénaliennes intra-testiculaires survenant lors d'hyperplasie des surrénales par bloc en 21 hydroxylase sont des tumeurs bénignes développées à partir de reliquats de tissu surrénalien. Elles sont fréquentes, asymptomatiques, volontiers multiples et bilatérales.

Histologiquement proches des tumeurs à cellules de Leydig elles ne contiennent pas de cristalloïdes de Reinke.

Elles sont liées à une stimulation chronique par l'ACTH et témoignent souvent d'une réponse insuffisante au traitement freinateur par les glucocorticoïdes.
Quels sont les mécanismes de l'hypofertilité ? Lors d'hyperplasie des surrénales par bloc en 21 hydroxylase l'hypofertilité est secondaire à 2 mécanismes :

- les nodules tumoraux réduisent et détruisent le parenchyme testiculaire sain et obstruent les canaux excréteurs (rete testis)

- la sécrétion excessive d'androgènes surrénaliens entraîne un hypogonadisme hypogonadotrope

\section{Quels sont les enjeux ?}

- Chez un homme présentant une hyperplasie des surrénales par bloc en 21 hydroxylase et une hypofertilité il est indispensable de rechercher des inclusions surrénaliennes testiculaires.

- La méconnaissance de ce diagnostic peut conduire à une chirurgie inutile et mutilante dans l'hypothèse d'une tumeur maligne des testicules.

- La découverte de ces inclusions conduit à intensifier le traitement, c'est à dire la freination de la sécrétion d'ACTH, afin d'en réduire le volume et d'améliorer la fonction des testicules. 


\title{
Le rhabdomiosarcome paratesticulaire
}

\author{
A. MALLEK, Y. MHADHEB, S. KETATA, A. BOUHLEL, A. SAHNOUN, A. BAHLOUL, M.N. MHIRI
}

Service d'Urologie CHU Habib Bourguiba, Sfax, Tunisie

\section{INTRODUCTION}

Le rhabdomyosarcome est une tumeur mésenchymateuse qui se développe à partir des structures conjonctives du voisinage du testicule. La localisation para-testiculaire est la plus fréquente des localisations génito-urinaires. Le but de ce travail est de déterminer ses particularités épidémiologiques, cliniques et pronostic.

\section{MATERIEL ET METHODES}

Notre étude est rétrospective faite sur une période de 22 ans (1982-2003), à propos de 4 observations de rhabdomyosarcome para testiculaire (RPT). L'âge moyen de nos patients est de 18 ans (10 à 23 ans). Le délai moyen de l'évolution des symtômes est de 2 mois (1 à 4 mois), ils ont consulté tous pour une grosse bourse d'évolution chronique. La taille moyenne de la tumeur est de $9 \mathrm{~cm}$ ( 6 à $17 \mathrm{~cm})$.

\section{RESULTATS}

Tous les malades ont eu une orchidectomie avec exérèse de la tumeur. L'examen histologique a confirmé le diagnostic; il s'agit d'un RPT embryonnaire dans 2 acs dont un incomplètement réséqué, de la forme polymorphe dans 1 cas et d'un RTP bien différencié dans 1 cas, tous deux ont été complètement réséqués.

Le bilan d'extension était négatif dans 2 cas est a montré la présence de ganglions retro péritonéaux dans 2 cas dont un avec des métastases pulmonaires.

Le pronostic était sombre malgré le traitement agressif comportant une chirurgie, une poly chimiothérapie adjuvante $(3 \mathrm{cas})$ et une radio thérapie adjuvante $(1 \mathrm{cas})$. En effet, 2 patients sont décédés après un délai de 2 mois dans un tableau de métastases diffuses, un a développé une rechute 2 ans après le traitement et un cas assez récent est encours de surveillance avec un recul de 6 mois.

\section{CONCLUSION}

Les rhabdomyosarcomes para-testiculaires sont des tumeurs malignes d'évolution rapide dont le diagnostic ne peut être que histologique. Leur pronostic reste, malgré la diversité des moyens thérapeutiques, fâcheux. 


\title{
La microlithiase testiculaire : pathogénèse et aspects cliniques
}

\author{
G. PASSAVANTI, V. PIZZUTI, E.SPINOSA, R. PAOLINI \\ Sce Urologie-Andrologie Hopital "Misericordia" Grosseto (Italie)
}

La micro-lithiase testiculaire (MTI) est une rare condition encore peu connu. Nous avons vérifié dans notre expérience, ses aspects cliniques et pathogenétiques. Trois personnes ont été soumis à une échographie testiculaire, dans deux cas pour un trouble de la fertilité (oligoasthénospermie au spermogramme) et dans un cas pour hémospermie et prostatite. Les trois sujets ont présenté une MTI à haute densité. L'échographie n'a pas démontré de lésions suspectes néoplasiques du testicule. L'âge des patients était 22, 27 et 33 ans. Chez 2 malades l'examen objectif et l'anamnèse étaient négatifs; un sujet avait été traité, pendant l'enfance, avec $\mathrm{Ca}$ et vitamines spécifiques pour le rachitisme. Les marquer (CEA; aFP, bhCG) étaient négatifs. Le suivi employait la palpation et l'échographie; depuis trois sessions de contrôles il n'a pas démontré nodules testiculaires. Le diagnostic de la MIT est simple avec l'échographie et elle permet de faire une classification selon la densité des calcifications.

1) Micro-lithiase isolée (d'origine inflammatoire, vasculaire ou post-traumatique) 2) Micro-lithiases à basse densité ( $<5$ micro-calcifications pour chaque scansion échographique) 3) Micro-lithiase à haute densité ( $>5$ micro-calcifications pour chaque scansion échographique). L'étiologie, la pathogenèse et les rapports avec la tumeur ne sont pas encore connus. Le diagnostic échographique différentiel est simple et il se pose avec les lésions hyper-échogènes du testicule (non pathologiques : ilum et medistinum testiculaires; pathologiques : tumeur, hématomes, atrophie segmentaire, torsion en phase aiguë, hydatide calcifiée). Sur le plan structural les micro-calcifications sont faites par hydroxyapatite, elles se développent sur les cellules dégénérées des tubes séminifère (spermatogones) et elles arrivent à un diamètre de $1-3 \mathrm{~mm}$. La maladie peut intéresser le $30-75 \%$ de tubes séminifères. Chez les sujets infertiles on trouve plus souvent la MTI; il n'est pas clair si l'obstruction des tubes séminifères est cause de l'infertilité ou si la dégénérescence des cellules tubulaires détermine soit lescalcifications soit le trouble de la fertilité. Dans notre casuistique, deux patients avaient une forme de MTI primitive et un sujet avait été traité avec $\mathrm{Ca}$ et Vit.D pour rachitisme; dans ce dernier cas nous nepouvonspas exclure que cette thérapie ait favorisé la MTI. En général la MTl a une incidence de $1 \%$ mais, chez les sujets avec troubles de la fertilité (en particulier les opérés pour cryptorchidie) elle a une incidence des $10-20 \%$ et dans notre casuistique deux patients avaient une oligoasthénospermie. La MTI est trouvée dans les testicules atteints par une tumeur dans les $30-40 \%$ des cas, mais, dans une population de sujets avec MTI on a trouvé unenéoplasie dans les $15 \%$ des cas. Donc il n'est pas clair si la MTI est associée au cancer du testicule ou si elle est une lésion pré-cancéreuse. Tous les auteurs concordent qu'il faut faire des contrôles tous les six-douze mois est dans notre casuistique aucun malade a manifesté une néoplasie du testicule pendant une suite de 18 mois à peu près. L'exiguiité de notre casuistique ne permet pas de poser conclusions significatives, d'ailleurs la MTI est une rare condition, on peut quand même relever que 2 sujets sur 3 avait un trouble de la fertilité et que nous n'avons pas relevé néoplasies testiculaires ni au début, ni pendant la suite. II faut signaler enfin l'hypothèse pathogenètique du troixième cas, ou la thérapie pour le rachitisme peut avoir favorisé la MTI. 


\title{
Intérêt de la cure de varicocèle chez l'adulte d'âge supérieur à $\mathbf{5 0}$ ans
}

\author{
A. MALLEK, N. REBAI, Y. MHADHEB, A. BOUHLEL, A. SAHNOUN, M.N. MHIRI \\ Service d'Urologie CGU Habib Bourguiba, Sfax, Tunisie
}

\section{BUT}

L'objectif de notre étude est d'établir le lien entre la cure de la varicocèle et l'amélioration des paramètres du spermogramme afin d'augmenter les chances de procréation chez des sujets porteurs de varicocèle dite "vieillie" et compliquée de stérilité.

\section{MATERIEL ET METHODES}

II s'agit d'une étude rétrospective portant sur 18 cas de varicocèle dite "vieillie". Le diagnostic était établi par écho doppler. L'indication opératoire était la stérilité dans tous les cas. La ligature chirurgicale des veines spermatiques a été réalisée soit par chirurgie conventionnelle (13 cas) soit par coeliochirurgie ( 5 cas). Deux patients étaient opérés pour varicocèle récidivante. Le spermogramme a été réalisé en préopératoire et 6 mois et 2 ans en post-opératoire.

\section{RESULTATS}

L'âge moyen des patients était de 64 ans (53-76). La stérilité était primaire dans $44.4 \%$ et secondaire dans $55,5 \%$. La varicocèle était bilatérale $(61,1 \%)$ et gauche $(38,9 \%)$. Elle était de grade II (9cas) et grade III (9cas) à l'écho doppler. Le taux d'amélioration de la numération et de la mobilité des spermatozoïdes et de réduction des formes atypiques était de $77,7 \%$, alors que le spermogramme reste invariable chez 4 patients. 11 grossesses évolutives ont pu être obtenues chez les partenaires (44\%) avec 3 deuxièmes grossesses survenant sur une période allant de 1 à 3 ans après la cure; tout en outre 7 des partenaires ont eu recours à une procréation médicalement assistée dont 2 couronnées de grossesses évolutives.

\section{CONCLUSION}

Ces résultats montrent bien l'intérêt du diagnostic et du traitement de la varicocèle dite "vieillie" chez les couples infertiles en l'absence des facteurs féminins associés. L'amélioration de la numération et de la mobilité des spermatozoïdes augmentait les chances de procréation. 


\title{
Le pseudo hermaphrodisme masculin (4 cas)
}

\author{
A. MALLEK, N. REBAI, Y. MHADHEB, A. BOUHLEL, A. SAHNOUN, M.N. MHIRI \\ Service d'Urologie CGU Habib Bourguiba, Sfax, Tunisie
}

\section{INTRODUCTION}

Le syndrome de "testicule féminisant" est la forme la plus fréquente de pseudo-herma-phrodisme masculin. Elle est caractérisé par une virilisation insuffisante de patients males. L'objectif de ce travail est de préciser les caractéristiques cliniques, biologiques et la conduite pratique devant cette pathologie.

\section{MATERIEL ET METHODES}

II s'agit d'une étude rétrospective à partir de 4 observations de pseudo-herma-phrodisme masculin colligées en 22 ans (1982-2004) dans notre service. L'âge moyen de découverte était de 14 ans (10 ans-17 ans). Nos quatre patients avaient un phénotype féminin ET la consultation était motivée par la non apparition de caractères sexuels secondaires. L'étude clinique avait montré l'absence de développement mammaire dans 4 cas, une hypertrophie clitoridienne avec ébauche d'un gland dans un cas et en fin une cryptorchidie bilatérale (4 cas - dont deux palpables). L'échographie a mis en évidence des testicules intra abdominaux chez les 4 patients. Le bilan hormonal avait révélé une augmentation des taux de LH (3cas) de FSH ( 3 cas), et une testosteronémie effondrée dans 4 cas. Tous les patients avaient un caryotype $46 \mathrm{XY}$ avec à l'étude des récepteurs androgéniques ( 2 cas) montre une nette diminution de la capacité de liaison.

\section{RESULTATS}

Une orchidectomie bilatérale par voie inguinale a été réalisée chez tous les patients avec génitoplastie féminisante (4 cas). L'examen histologique avait conclu à un testicule avec hyperplasie des cellules de LEYDIG dans les 4 cas, associé à un séminome in situ bilatérale dans 1 cas.

\section{CONCLUSION}

II s'agit d'une affection très rare dont le traitement se résume en une chirurgie d'exérèse des gonades cryptorchides. Le diagnostic doit être aussi précoce que possible pour éviter toute erreur de détermination du sexe dans lequel l'enfant sera élevé, avec des conséquences psychologiques et somatiques graves, en outre il permet de déterminer et traiter tout cancer testiculaire sur testicules ectopiques. 


\title{
Les cellules neuro-endocrines du veru montanum : étude comparative immunohistochimique
}

\author{
L. GUY1,2, L. BEGIN2, K. AL-OTHMAN2, S. CHEVALIER2, J.P. BOITEUX1, A. APRIKIAN2
}

1 Service d'Urologie, CHU Clermont-Ferrand, 2 Institut de recherche et service d'Urologie de l'Hopital Général de Montréal, Canada

\section{OBJECTIF}

Définir la distribution des cellules neuro-endocrines dans les différentes parties du veru montanum (utricule, canaux éjaculateurs, canaux prostatiques) comparativement aux autres zones de la prostate.

\section{MATERIELS ET METHODE}

Etude rétrospective de 30 pièces de prostatectomies radicales montées en prostate totale. Parmi ces 30 cas, 15 patients avaient reçu une hormonothérapie pré-opératoire de 3 mois. La distribution et le nombre de cellules neuroendocrines dans l'utricule et dans les autres zones anatomiques de la prostate ont été analysés en utilisant une immunohistochimie Chromogranine $A$ et sérotonine ; un marquage anti-PSA était également utilisé de façon systématique sur coupe adjacente.

\section{RESULTATS}

Un nombre significativement plus élevé de cellules neuroendocrines était noté au niveau de l'utricule prostatique comparativement aux canaux prostatiques principaux et aux acini prostatiques périphériques. Dans les canaux éjaculateurs, les cellules neuro-endocrines étaient seulement présentes au niveau de leur portion la plus distale. Les cellules immunoréactives pour le PSA étaient présentes au niveau de l'utricule et également à la partie la plus distale des canaux éjaculateurs. La distribution, le nombre et la forme des cellules neuro-endocrines n'étaient pas modifiés par le traitement hormonal.

\section{CONCLUSION}

La forte concentration des cellules neuro-endocrines trouvées dans l'utricule prostatique permet d'envisager un rôle de ces cellules dans les phénomènes de fertilité. 


\title{
Intérêts de la vésiculographie chez l'homme infertile
}

\author{
F. BRUGNON, L. JANNY, J. HERMABESSIERE \\ Laboratoire de Biologie de la reproduction, CECOS, CHU, Clermont Ferrand
}

\section{INTRODUCTION}

La vésiculographie est un examen d'imagerie particulièrement indiqué lors de toute intervention pour infertilité masculine comportant un abord scrotal.

L'opacification est réalisée par abord chirurgical au bloc opératoire des déférents et injection de $2,5 \mathrm{CC}$ de liquide hydrosoluble contenant des antibiotiques. Une radiographie est effectuée immédiatement après l'injection, puis à un intervalle de 5 minutes.

\section{RESULTATS}

Nous rapportons les photos de différents aspects pathologiques observables par cet examen d'imagerie : infection subaigue ou chronique, abcès calcifié, reflux post-opératoire sur urétrographie, kyste, malformations congénitales.

\section{DISCUSSION}

Les indications actuelles de la vésiculographie sont peu fréquentes. En effet, l'échographie transrectale a remplacé la radiographie dans notre pratique. Néanmoins, la vésiculographie reste indiquée avant une chirurgie par voie urétrale ou haute. L'imagerie par résonance magnétique (IRM) n'étant pas encore examen de routine, la vésiculographie garde quand même des indications.

\section{CONCLUSION}

La vésiculographie est un examen d'imagerie qui, même si les indications sont tres limitées, a gardé une place dans le bilan d'exploration diagnostic de l'homme infertile

\section{REFERENCES}

1. HERMABESSIÉRE J., ROCHE G., VIALLET JF., USSEIL C. (1977) vésiculographie chez l'homme infertile. Rev. Franc. Gynec.72, 645-651.

2. BOREAU J. (1974) Les images des voies séminales. Bâle, Karger. 


\title{
Evaluation de la fonction érectile après chirurgie de l'hypertrophie bénigne de prostate
}

\author{
L. SAVAREUX1, L. GUY1, S. BOISGARD2, J.P. BOITEUX1 \\ 1 Service d'Urologie, CHU Clermont-Ferrand, 2 Service d'Orthopédie, CHU Clermont-Ferrand
}

\section{INTRODUCTION}

La chirurgie de I'hypertrophie bénigne de la prostate (HBP) est habituellement considérée comme une chirurgie sans conséquence sur la fonction érectile. II n'existe cependant pas d'étude comparant la qualité de la fonction érectile après chirurgie de l'HBP versus une autre chirurgie fonctionnelle. L'objectif de notre étude était d'étudier la fonction érectile de patients traités chirurgicalement pour une HBP et de la comparer à une population bénéficiant d'une arthroplastie des membres inférieurs.

\section{PATIENTS ET MÉTHODE}

L'étude réalisée est une étude prospective, comparative, effectuée de Mars 2001 à Octobre 2002. Elle a inclus un total de 100 patients âgés de 50 à 80 ans. La fonction érectile de 50 patients opérés d'une HBP a été comparée à celle de 50 patients opérés d'une arthroplastie. Le critère d'évaluation utilisé a été le questionnaire modifié de l'Index International de la Fonction Erectile (IIEF) avec 7 questions. Une question supplémentaire concernant les modifications post opératoire de l'orgasme a été ajoutée. Un interrogatoire par le même investigateur a été mené la veille de l'intervention et à 3 mois dans les 2 groupes. L'analyse statistique est réalisée à l'aide du test du Chi-Deux $(p<0,05)$ et du test de Fisher.

\section{RESULTATS}

Les 2 populations étaient homogènes pour l'âge et le score de l'Association Américaine d'Anesthésie (ASA). La comparaison des items pour les 2 populations ne mettaient pas en évidence de différence significative. II n'était pas non plus mis en évidence de différence significative entre le statut érectile pré et post opératoire des patients porteurs d'une HBP. II était par contre constaté que $6 \%$ des patients opérés dans les deux populations objectivaient une altération de leur érection et alors que $6 \%$ des patients opérés en Urologie objectivaient une amélioration de leur érection.

\section{CONCLUSION}

La chirurgie de I'HBP n'est pas plus délétère que tout autre acte chirurgical. Elle peut même améliorer le statut érectile d'une minorité, non significative, de patients. 


\title{
Devenir sexuel des patients opérés par dérivation urinaire externe continente
}

\author{
A. MALLEK, Y. MHADHEB, A. BOUHLEL, H. FAKHFAKH, M.N. MHIRI \\ Service d'Urologie CGU Habib Bourguiba, Sfax, Tunisie
}

\section{INTRODUCTION}

Le profil sexuel des patients porteurs d'une dérivation urinaire est influencé par plusieurs facteurs. II incluse, entre autre, la nature de la dérivation et la réadaptation qu'elle permet. La DUEC de type MITROFANOFF est un type de dérivation urinaire qui s'adapte bien à notre contexte socio-économique. On se propose de préciser les résultats et les conséquences qui en résulte concernant la sexualité des patients qui en sont bénéficiaires.

\section{MATERIEL ET METHODES}

Notre étude est rétrospective réalisée sur une période de 12 ans s'étalant entre janvier 1992 et décembre 2003. Elle a inclus 23 patients, dont 5 de sexe féminin.

L'âge moyen est de 29 ans (25-67 ans), le sex ratio est de 3,6. 2 patients sont diabétiques depuis l'enfance sous insulinothérapie.

Les indications de la dérivation urinaire sont représentées essentiellement par les vessies neurologiques. Par ailleurs, notre série est formée de 4 femmes et de 5 hommes mariés, de 13 hommes célibataires dont 12 sexuellement actifs et d'une jeune fille sexuellement inactive. Un questionnaire leur a été posé concernant leurs qualités de vie quotidienne (sociale et familiale).

\section{RESULTATS}

Le recul moyen est de 48 mois ( 4 ans) (6 à 144 mois).

Tous les patients mariés estimaient que leur vie sexuelle s'est rééquilibrée après l'intervention notamment après s'être débarrassé des séquelles de l'incontinence d'urine. Le désir et l'orgasme ont été mieux ressentis avec satisfaction du partenaire.
Parmi les 13 célibataires, 3 signalent un déséquilibre sexuel persistant en postopératoire. Les raisons de cette perturbation étaient dues à la pathologie initiale (myélite vasculaire compliquée de paraplégie dans 1 cas, et un diabète au stade de complications dégénératives dans 2 cas). En outre, nous avons noté 2 mariages après 7 ans de l'intervention avec satisfaction des couples.

En somme, tous les patients interrogés sont très satisfaits de l'intervention pour des raisons hygiéniques, parmi eux, $20(87 \%)$ ne ressentent aucune répercussion psychologique, en effet ils ne ressentent pas d'atteinte de l'intégralité de leurs images corporelles.

\section{CONCLUSION}

Nous estimons, au vue de nos résultats et une revue de la littérature qui est très limitée, que la DUEC de type MITROFANOFF est un moyen efficace, pour certains patients motivés, pour avoir un bon équilibre de leur vie sexuelle. 


\title{
Insuffisance de désir sexuel chez l'homme. Intérêt du bilan hormonal. A propos de 59 patients
}

\author{
D. DELAVIERRE
}

Uro-andrologue, CHR d'Orléans, France

\section{INTRODUCTION}

L'insuffisance de désir sexuel est définie par l'insuffisance ou l'absence persistante ou récurrente de désir d'activité sexuelle solitaire ou avec partenaire(s) et/ou de fantasmes sexuels conscients et excitants, responsable d'une souffrance personnelle (30éme Séminaire de l'AlHUS 2000).La prévalence de cette dysfonction est comprise entre 15 et $25 \%$ selon diverses enquêtes épidémiologiques.

\section{MATERIEL ET METHODES}

Du 1er/01/00 au 31/03/04 65 patients âgés de 28 à 73 ans (moyenne 52) ont consulté en raison d'une insuffisance de désir sexuel (à l'exclusion des insuffisance de désir sexuel secondaires à d'autres dysfonctions sexuelles). 47 patients $(72 \%)$ présentaient des facteurs de risque psychologiques (surtout contexte anxio-dépressif, stress, difficultés conjugales, traumatisme psychologique après maladie ou intervention) et $15(23 \%)$ prenaient des médicaments (surtout psychotropes) dont l'insuffisance de désir sexuel est un effet secondaire potentiel. Chez tous les patients un bilan hormonal a été prescrit : testostéronémie - biodisponible 55 patients, totale 10 patients - et prolactinémie mais 6 patients n'ont pas effectué le bilan. 59 patients ont donc été évalués.

\section{RESULTATS}

Parmi les 59 patients évalués le bilan était normal chez 48 $(81 \%) .2$ patients $(3 \%)$ présentaient une prolactinémie > $25 \mathrm{ng} / \mathrm{ml}$ et un prolactinome hypophysaire a été diagnostiqué dans les 2 cas (pas d'orientation clinique préalable). Malgré le traitement du prolactinome les 2 patients ont conservé une insuffisance de désir sexuel (présence de facteurs de risque psychologiques). 9 patients (15\%) pré- sentaient un hypogonadisme (testostéronémie totale $<3$ $\mathrm{ng} / \mathrm{ml}$ ou biodisponible $<0,8 \mathrm{ng} / \mathrm{ml}$ ) sans hyperprolactinémie. Le bilan orientait vers un hypogonadisme périphérique - 4 patients - ne retrouvait aucune anomalie - 3 patients - ou n'a pas été effectué - 2 patients perdus de vue. Une androgénothérapie a été prescrite chez 4 patients : 1 succès, 1 échec (présence de facteurs de risque psychologiques) et 2 non évalués. 3 patients n'ont pas été traités mais 1 a guéri spontanément.

\section{CONCLUSION}

Sur le plan diagnostique le bilan hormonal d'une insuffisance de désir sexuel chez l'homme semble intéressant ( $19 \%$ d'anomalies dont $3 \%$ de prolactinomes) mais sur le plan thérapeutique l'intérêt de ce bilan est plus réservé en raison notamment de facteurs de risque psychologiques concomitants. 


\title{
Effets des polyphenols contenus dans l'huile des noyaux des dattes sur la mobilité des spermatozoï- des exposés à un stress oxydant in vitro
}

\author{
F. BEN ABDALLAH, N. FEKI CHAKROUM, L. KESKES, I. KAMOUN, S. BESBES, H. ATTIA, \\ C. BLECKER, B. HENTATI, T. REBAI
}

Institut de Biotechnologie de Sfax. Unité de recherchedes pathologies et stress oxydatif, unité de chimie générale et organique, unité d'analyse alimentaire. Laboratoire d'histologie Embryologie, Faculté de Médecine de Sfax

L'huile des noyaux de dattes (HND) est un mélange naturel d'antioxydants contenant surtout des polyphénols. Des travaux étudiant son action antioxydante sur des cellules de mammifères en culture sont en cours dans nos laboratoires. Dans ce travail notre objectif était de tester l'effet de I'HND sur la mobilité et la vitalité des spermatozoïdes humains exposés à un stress oxydant in vitro.

Nous avons utilisé des spermatozoïdes mobiles sélectionnés à partir des échantillons de spermes de caractéristiques normales par des gradients de SillSelect $(n=4)$. L'absence de toxicité de HND (de 0.1 à $0.01 \%$ HND dissoute dans la gomme arabique) sur les spermatozoïdes en culture a été vérifié par le test de vitalité. Chaque préparation de sperme a été aliquotée en quatre échantillons: Echantillon 1 : Eo, le témoin, les spermatozoïdes ont été incubés dans le ferticult, Echantillon 2 (E1) : les spermatozoïdes ont été incubés avec $\mathrm{H} 2 \mathrm{O} 2$ seule $(0.01 \mathrm{mM}) 30 \mathrm{~min}$ et 24 heures, Echantillon 3 (E2) : les spermatozoïdes ont été incubés HND seule $(0.01 \%)$, Echantillon 4 (E3) : les spermatozoïdes ont été incubés successivement avec HND $(0.01 \%)$ pendant 15 min puis avec $\mathrm{H} 2 \mathrm{O} 2(0.01 \mathrm{mM})$ pendant 24h.

En présence d'HND (E3) la mobilité progressive des spermatozoïdes à 30 min et la survie à 24 heures sont comparables à EO. Les spermatozoïdes incubés avec $\mathrm{H} 2 \mathrm{O} 2$ en présence de HND (E3) maintiennent une mobilité progressive et une survie par rapport à ceux exposés à $\mathrm{H} 2 \mathrm{O} 2$ (mobilité progressive en moyenne $40 \%$ vs $5 \%$ à $30 \mathrm{~min}$ et $30 \%$ vs $0 \%$ à 24 heures respectivement).

Ces résultats préliminaires seront complétés par la confirmation de l'effet antioxydant de HND et particulièrement des polyphénols sur les caractéristiques spermatiques en étudiant les marqueurs du stress oxydant dans les spermatozoïdes (dosage du MDA et des ROS), ainsi par une étude complémentaire sur l'effet protecteur probable de HND vis à vis de l'ADN spermatique sera envisagée. 